\title{
Nanotechnology Applications Towards Sustainable Road Sur- face Maintenance and Effective Asset Protection, Generating Rapid Employment Opportunities in a Post COVID-19 Era
}

\author{
Gerrit J Jordaan ${ }^{1,2, *}$ and Wynand J vdM Steyn ${ }^{3}$ \\ 1 Department of Civil Engineering, University of Pretoria, Pretoria 0002, South Africa \\ 2 Jordaan Professional Services (Pty) Ltd., Pretoria 0062, South Africa \\ 3 School of Engineering and Department of Civil Engineering, University of Pretoria, Pretoria 0002, \\ South Africa; Wynand.steyn@up.ac.za \\ * Correspondence: jordaangj@tshepega.co.za; Tel.: +27-(0)-824164945
}

\begin{abstract}
The developing world has been faced with high rates of unemployment, exasperated by extended enforced lockdowns due to the Pandemic. Pressure is mounting for drastic intervention to accelerate economic growth and to provide employment opportunities. Most of these countries are faced with inadequate road transport facilities in support of economic growth. The construction of high-order roads in support of economic growth, require high degrees of compliance with limited opportunities for increased the labour content. However, many of the existing surfaced roads are notoriously lacking periodic preventative maintenance operations needed to preserve the integrity of road surfaces to protect pavement structures against water ingress and resultant rapid deterioration. This article demonstrates the ability of available, proven nanotechnologies to restore the waterresistant properties of already compromised road surfacings. It is shown that traditionally used road products can substantially be improved (in terms of strength properties and resistance to environmental factors) through the addition of applicable nanotechnology modifiers. These modified products can be applied at ambient temperatures, ideally suited for labour intensive applications as demonstrated, showing several examples of actual applications. A combination of modified existing technologies is recommended to partially restore severely compromised road surfacings, especially applicable to secondary, tertiary and urban road networks. The implementation of the recommended restoration programmes can go a long way towards road asset preservation, while simultaneously, addressing the urgent need for rapid employment generation.
\end{abstract}

Keywords: Nanotechnology applications in road maintenance; preventative road surface maintenance; nanotechnology clear-seals; New-age (Nano) Modified Emulsions (NME); pothole repairs; modified bitumen emulsion slurry seals; hydrophobic modified binder slurries; hydrophobic road surface sealants; labour intensive periodic maintenance; rapid employment for preventative road maintenance.

\section{Introduction}

The developing world is faced with high unemployment statistics, exasperated by extended lockdown of economies enforced by the world-wide Pandemic. Governments are under increasing pressure from the electorate to create job opportunities with increased expenditure on infrastructure projects and to create an environment for economic growth. A prerequisite for economic growth is a transportation infrastructure supporting economic actives, giving access to markets, etc. Hence, Road Authorities are also under increasing pressure to increase the labour component of road infrastructure projects. The construction of high-order primary roads in support of economic growth, require high degrees of compliance with engineering specifications and it is often difficult to increase the labour content on these projects. 
The increase in the labour component of lower-order roads is more easily achieved, where the expected level of service, in line with the number of vehicles to accommodate, are of lesser importance as a component to economic growth. However, an often-overlooked component for increased labour-intensive operations on road networks, are the periodic maintenance of the existing surfaced roads. Periodic maintenance (also known as preventative maintenance), are notoriously lacking in numerous countries, often leading to premature distress and the destruction of valuable road infrastructure assets. In the absence of Maintenance Management Systems (MMS's) the integrity of road surfacings are relatively soon compromised (compared to the original road structure design period) due to the ageing effect (environmental impact) of the surfacing binder, leading to cracking, water ingress into the road pavement structure resulting in accelerated premature distress in the form of cracking, surface disintegration and potholes. In effect, the absence of MMS's, can directly be associated with the destruction of valuable state assets (roads) which directly supports economic growth.

The introduction of any new disruptive technology [1] in a traditionally well-established industry such as the road industry, is usually associated with considerable resistance. This is especially relevant when the new technology is based on the use of relatively new concepts not traditionally associated with the road infrastructure industry such as nano-silanes, hydrophobicity, nano-polymers and New-age (Nano) Modified Emulsions (NME). These concepts are all relatively new in the road industry, although most (if not all) of these concepts and products have been used successfully in the built-environment decades, some since the 1800s [2,3,4], to protect stone buildings from the destructive effect of adverse weather (water) conditions. The applicability of proven nanotechnologies had been identified [5] for use in roads more than a decade ago and proven in laboratories $[6,7,8,9]$ beyond reasonable doubt over the last two decades.

Over the last decade the use of material compatible NME technologies for the stabilisation of marginal granular materials have been proven through Accelerated Pavement Testing (APT) $[10,11,12]$ and in practice $[7,13]$. Simultaneously, the fundamental requirements [14] for NME products and scientifically based design concepts have been developed and published in international peer-reviewed reputable journals $[15,16]$ to ensure that these technologies can be universally applied without risk to life and the environment. Risks to pavement design engineers are also minimised in terms of future pavement materials behaviour, durability and cost implications using life-cycle cost analysis incorporation probabilistic theories [17]. In fact, the adoption of design concepts incorporating material compatible NME nanotechnology solutions have been shown to reduce the provision of sustainable road transportation infrastructure by more than 50 per cent $[11,12]$. Data also shows a considerable reduced damage caused by overloading (of high importance in the absence of law-enforcement in terms of heavy-vehicle overloading), compared to traditional pavement structural design approaches [11,12].

These same applicable nanotechnologies proven for the construction of road pavement layers are just as suitable for the periodic, preventative maintenance and protection of existing roads. Road surface maintenance is a well-documented problem, especially in the developing world, where little capacity in terms of sustainable periodic, preventative maintenance programmes exists. The expected distress-free durability of bituminous surfacing materials on roads under harsh environmental conditions (exposure to high ultraviolet radiation and high temperature variations normally experienced between the tropics and in the desert areas of the world) are normally much less than the design period of road pavement structures of 20 years or more. If left unattended, in the absence of good MMS's, these roads surfaces will develop environmental-related cracking that will soon deteriorate into surface disintegration and roads inundated with potholes in the presence of water and vehicle loading. It follows that any breach in the integrity of the road surface will result in considerable premature structural damage and the effective destruction of considerable investments in road infrastructure. This scenario is all too familiar and common in many parts of the world in dire need of economic development and associated employment opportunities. 
Traditionally used preventative maintenance actions are usually associated with the placement of new surfacings (e.g. chip-seals), applying high-temperature bituminous products. In the same vein, traditionally used mixes for pothole repairs, or the re-instatement of surface damage, comes at considerable cost. These "cold-mix" products are notoriously expensive and difficult to use under low-temperature conditions (below $20^{\circ} \mathrm{C}$ ), resulting in relatively low compacted densities and highly porous surfacings. Hence, water penetration into these reinstated surfacings is relatively easy with a resultant quick deterioration in condition and the re-appearance of the potholes, usually with increased extent and dimensions.

The adoption of proven nanotechnologies for the stabilisation of granular pavement layers [16], also applicable to road surface maintenance, could be key to the reversal of scenario of road pavement pre-mature distress due to compromised road surfaces. The objectives of this article are to:

- Demonstrate the advantages that can be achieved using applicable, safe nanotechnology solutions for periodic/preventative maintenance, specifically with regard to the quantification of the water-repellent (hydrophobic) ability of these technologies;

- Recommend applicable modified binder products suitable to address road surface distress when the integrity of the road surface has already been compromised, allowing water ingress into the pavement structure and associate development of distress, and

- Demonstrate the suitability of nanotechnology solutions to road preventative and routine road surface restoration activities, for labour-intensive applications, creating rapid employment opportunities.

The considerable benefits in terms of depth of penetration (due to small particle sizes) of nano-based products, ease of application (little training required) and the proven high degree of hydrophobicity (water-repellent characteristics) [14] are ideally suited to costeffective labour-intensive maintenance actions, exceeding the performance of traditionally used preventative maintenance products. The nanotechnology solutions are also to present the ability to partially restore roads (especially applicable to secondary, tertiary and urban roads) where the surface integrity has already been compromised, exhibiting continuously increasing surface cracking, disintegration and pothole formation, at a fraction of the costs of partial reconstruction so often required.

\section{Applicable Nanotechnology Solutions to Road Maintenance}

The applicable use of safe nanotechnology solutions for the labour-intensive maintenance of existing roads are shown in terms of the:

- Protection of and restoring of the surface integrity of existing road surfaces through the application of applicable hydrophobic Nano-Polymer Nano-Silane (NPNS) "clear-seal" nanotechnology solutions, the effect of which is demonstrated (under extreme conditions), on an:

- Unsurfaced unprotected compacted laterite soil (common weathered material found between the tropics) [16];

- Unprotected compacted high-quality crushed stone pavement base-layer with no prime or any other surfacing, and

- Existing surfaced road with the integrity of the road surface already severely compromised, exhibiting severe crocodile cracking (also known in some parts of the world as alligator cracking);

- Effective repair of roads containing multiple potholes using pre-packed anionic NME repair pothole kits to create a hydrophobic restored road surface, which are easy to use, requiring the minimum of effort and training, and

- The resealing of the road using a hydrophobic anionic NME modified binder slurry seal to restore some deformities in the wheel-tracks and produce a labour-intensive, hydrophobic, cost-effective, water resistant and durable surfacing.

All of these road surface periodic maintenance and restoration actions can easily be performed using labour-intensive operations, requiring the minimum training. In light of 
high unemployment rates in many parts of the world, there is a heightened need to create employment through infrastructure investments. The introduction of nanotechnology solutions for the effective maintenance and restoration of road networks can result in the creation of rapid employment opportunities with considerable advantages in terms of road asset protection.

\section{Fundamental Principles Applicable to the Selection of Nanotechnology Solutions Suitable for Road Surface Maintenance}

\subsection{General}

The understanding of the benefits to be gained and the principles associated with the use of new-age nanotechnologies are crucial to the successful introduction thereof in the roads industry. General concerns in terms of issues such as health and safety obviously need to be addressed. The general adoption of new technologies is closely linked to the ease of application, not requiring complicated procedures (e.g., similar to the successful introduction of new telecom (cellular phones) and IT devices (laptops)).

The same principles will apply to the introduction of new technologies in the roads industry. Of considerable importance in the era following the devastating impact of the Covid 19 Pandemic, is the ability to provide more employment opportunities without considerable investments in advanced training. These elements could prove critical in the fast-tracking of new nano-technologies in a top-down policy approach, especially if advantages in the use of the new technologies can be shown to be superior in performance compared to traditionally used methods and products (even in a conservative environment such as the roads construction and maintenance industry).

It follows that the basic criteria to ensure that nanotechnology solutions are successfully implemented, must be clearly identified and assessed in the line of intended application, i.e. in this case, sustainable and improved road maintenance actions (products together with application methods), resulting in cost-effective road-asset preservation.

The following fundamental basic characteristics associated with available, proven and/or new nanotechnologies, will ensure that risks are minimised through the introduction of these technologies in the road maintenance environment [14]:

- Toxicology, health and safety of the use of various nano-scale products;

- Environmental aspects, leaching and affecting ground-water;

- Nanotechnology products as a binder and/or sealer;

- Stability of the nano-modified stabilising agent in a carrier fluid, e.g., water for dilution and ease of application, suitable for labour-intensive applications;

- Quantity (volume) of the nano-silane to be added, as influenced by the relative surface area or coverage needed to achieve the required characteristics of surface integrity - this aspect could be closely related to the condition of the existing surface that could be worse in the wheel-tracks than outside the wheel-tracks;

- Hydrophobic characteristics as required with the addition of the nano-silane to the nano-polymer for road surface maintenance;

- $\quad$ Compatibility aspects of nano-silanes and nano-polymers to provide a stable product resistant to degeneration;

- Engineering evaluation of the effect of Nano-Silane Nano-Polymer (NPNS) hydrophobic (water-proofing) qualities and the required stability, quick drying and engineering strength criteria of durable NME pothole repair mixes (i.e., compressive strengths, tensile strengths and durability), and

- Cost-aspects associated with the use of new nanotechnology-based products for periodic preventative and restoration maintenance of existing roads.

Every one of these aspects are of importance in the evaluation of new nanotechnology-based products and discussed in detail in the References 14. However, some aspects of high importance to the road industry and labour-intensive applications (with specific reference to toxicology, health and safety) and environmental impact of the use of various 
nano-scale products are expanded upon in short. Only aspects of importance to road surface maintenance (complimentary to the above) are illustrated for clarity of understanding of the various concepts.

\subsection{Toxicology, health safety and environmental impact}

It should be noted that many of these NPNS based products are generally available and used in the built environment and form the basis of numerous of the latest Do-It-Yourself (DIY) products generally available and sold to the public. These products include sealants (water-repellent agents that are strayed onto walls of houses to avoid and prevent water-ingress and damage to houses), adhesives and paints, etc. utilising the "excellent mechanical, optical, thermal and electrical properties" of these organofunctional nanosilanes. Generally these products show typical conditions for safe applications an example of which is shown in Figure 1. These protective recommendations are usually also applicable to routine road maintenance activities (e.g. grass cutting), and road construction activities using bituminous products.

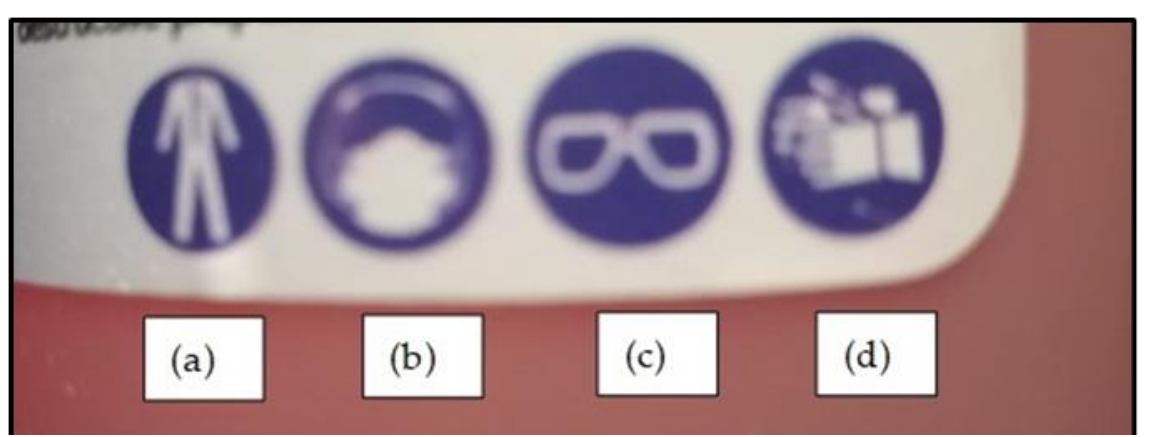

Figure 1: Normal recommendations found on DIY products generally available in hardware stores for the water-proofing of houses; (a) Overalls; (b) Mask; (c) Eye-protection; (d) Gloves.

However, it should be noted that these products for the protection of stone buildings originated in Europe [2,3,4] and good-quality products will meet the health and safety and environmental regulations in-place in the European Union (EU). Many silane couplings, which are freely available commercially, will form siloxane bonds. However, of these, only a few known nano-silanes will have the "correct balance of volatility and reactivity without being harmful to society" or to the materials being treated [4]. Hene, it is of importance to take cognicance of the the "Safety Sheets" when selecting an appropriate safe product similar to the selction of any "safe" house-hold cleaning agent.

Two chemical processes are usually applicable with the addition and use of nanoscale products in the built environment. The first occurs during the mixing thereof with a carrying fluid during any construction/maintenance activity, (referred to as a process of hydrolysis) (e.g., mixing with water) and secondly, during condensation (when the product attaches to the material during treatment or stabilisation). During any of these two processes by-products can be formed. It must be ensured that any nano-scale product used, does not generate any by-product (liquid or gas) that may be toxic in any way. The by-product formed during the hydrolysis process of the nano-silane when in contact with water, is of fundamental importance in the selection of an appropriate and applicable nano-silane to be used in general engineering projects [4]. The most appropriate and designed alkoxy-silanes will form water as a by-product or at the worst, a non-corrosive alcohol [4].

Alkoxy-silanes (also referred to as organo-functional silanes due to the water-repellent molecule attached to the silicon element) generally available for water-proofing of buildings, have low vapour pressures and do not form toxic gasses or acids during hydrolysis. Similarity, the approved products used for the treatment of buildings/houses, etc (e.g. DIY products) forms water as a by-product during consolidation (attachment onto the surfacing, forming a three-dimensional matrix covering all exposed surfacings it has 
been chemically designed to attach to [15] - it will, for example, not attach to exposed skin, as will be demonstrated.

From an environmental point of view, the alkoxy-silane is bound to the sub-strata through chemical bonds (e.g. Si-O-Si bonds - one of the strongest in nature) (in the case of silicon rich materials - the $2^{\text {nd }}$ most abundant element in the crust of the earth after oxygen). Using naturally available materials containing few or no free silicon elements to effect silicon bonds (e.g., calcretes or severely weathered laterites), an applicable Hydroxy Conversion Treatment (HCT) [15] nano-product should be added to the compatible nanosilane, ensuring that chemical bonds of similar or stronger strengths are achieved [15].

It follows that recommended nano-silanes based products must be scientifically designed to strongly attach chemically to the generic fingerprint of the minerals contained in the materials that are being treated, resulting in no risk of leaching and/or contamination. In fact, the alkoxy-silane modification of traditionally used binders, such as bitumen (as contained in, e.g., bitumen emulsions to form anionic NME products), will firmly attach the bitumen to the stone/aggregate/soil, preventing any bitumen from detaching from the soil and cause any contamination. The same principle also applies to the modification of bitumen for use in asphalt manufacturing. The modification of the binder sing a material compatible nano-silane product (EU compliant), will assist greatly to prevent or at least minimise any possible future leaching and contamination cause by the binder in the asphalt surfacing of roads.

\subsection{Particle size and the effect on road surface maintenance}

The main objective of road periodic (preventative) surface maintenance is to protect and/or restore the integrity of the surfacing to prevent secondary distress. The larger the particle sizes of the products used for road surface maintenance, the less would be the depth of influence on the road surface. This aspect is visually demonstrated in Figure 2.

From Figure 2 it is seen that surface rejuvenators (e.g. diluted bitumen emulsions), comprise of particle sizes between 2 and $5 \mu \mathrm{m}$ (similar to most of the available polymers), will seal some micro-cracking with little in-depth penetration and protection of the surfacing and with hence, a limited effect on the restoring of the integrity of the road surface. It is well-known that the use of rejuvenators as a road surface maintenance action, will increase the durability of the road surfacing for a year or two only. In the case of the use of a diluted bitumen emulsion, road markings will be affected and will have to be re-instated as a road-safety measure. In contrast, the use of a clear-seals (diluted NPNS), will show much deeper penetration with a longer-lasting effect.

\subsection{Water-repellent (hydrophobic effect) of nano-silanes}

In terms of road surface maintenance, resistant to water damage is of cardinal importance. Any penetration of water into micro-cracks will, under the action of traffic loading, develop large pore-pressures able to quickly destroy the integrity of the road surfacing. The result is an accelerated deterioration and the development of pumping of fines from the supporting base-layer. If not addressed immediately, potholes will develop with severe safety and cost implications. A major advantage of the use of material compatible nano-silanes, is that the surface of the material it attaches to is changed to become hydrophobic and it will repel water. This water-repellent nature is demonstrated in Figure 3. 


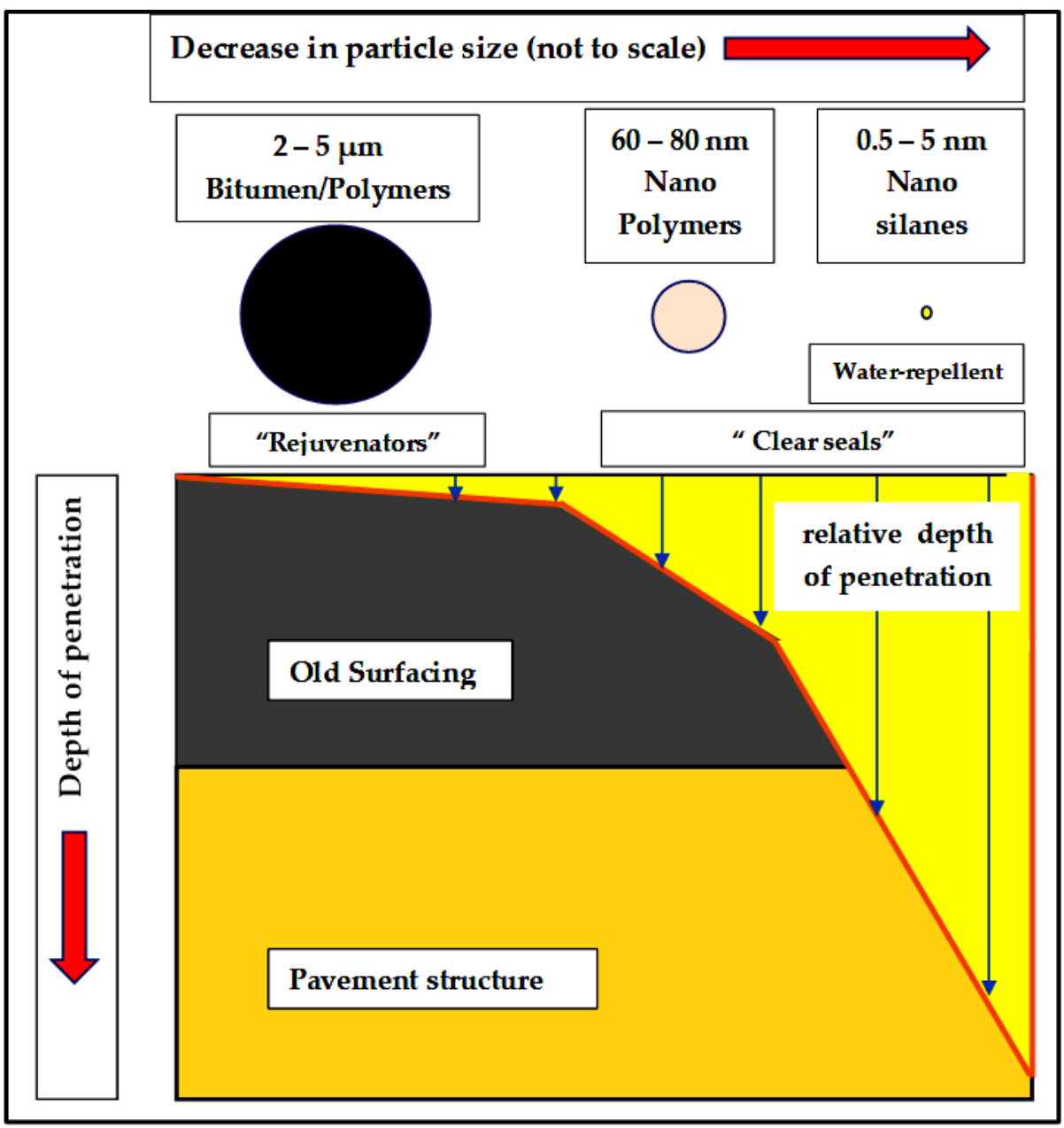

Figure 2: Effective penetration using rejuvenators (diluted bitumen emulsions) in comparison to "clear-seals", i.e. Nano-Silanes modified Nano-Polymers (NPNS) of different particle sizes for the treatment of old road surfacings (same surface condition).

\section{Water repellent: Beading effect}

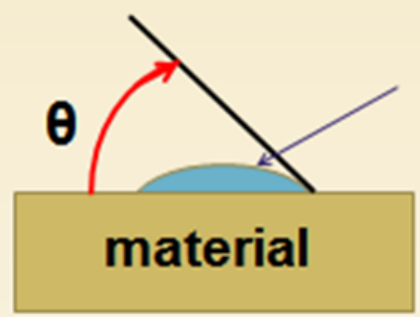

$\theta=0^{\circ}-90^{\circ}$

$\operatorname{Cos} \theta=1$ to 0 Hydrophilic

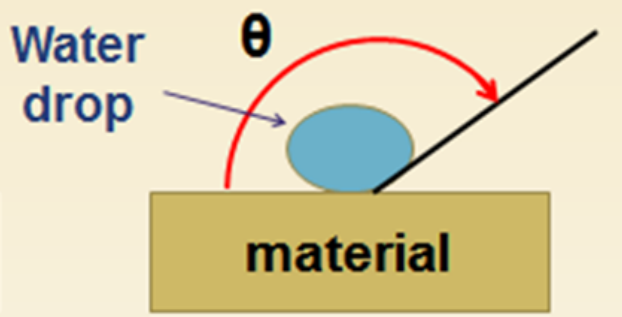

$\theta=90^{\circ}-180^{\circ}$

$\operatorname{Cos} \theta=0$ to -1 Hydrophobic

Figure 3: "Beading" of water droplets showing the hydrophobic (water-repellent) nature of a nanosilane treated surfacing of a material. 
The practical effect of the treatment of a material with a material compatible nanosilane is shown in Figure 4, with the treatment of black-cotton soil. The treated material has been broken into small pieces and although gaps exist between the separate material (treated black-cotton clay) pieces, the water drops do not penetrate the material or gaps and form beading on the top of the nano-silane treated material. The same effect is achieved with the treatment of other materials such as fine-grained sands, where water drops will remain suspended on top of the sand as shown in the inset (b) in Figure 4 . In this case the "glue" in the NPNS, i.e. the nano-polymer, is not present to bind the particles together and create the strength as part of a material compatible NPNS treatment.

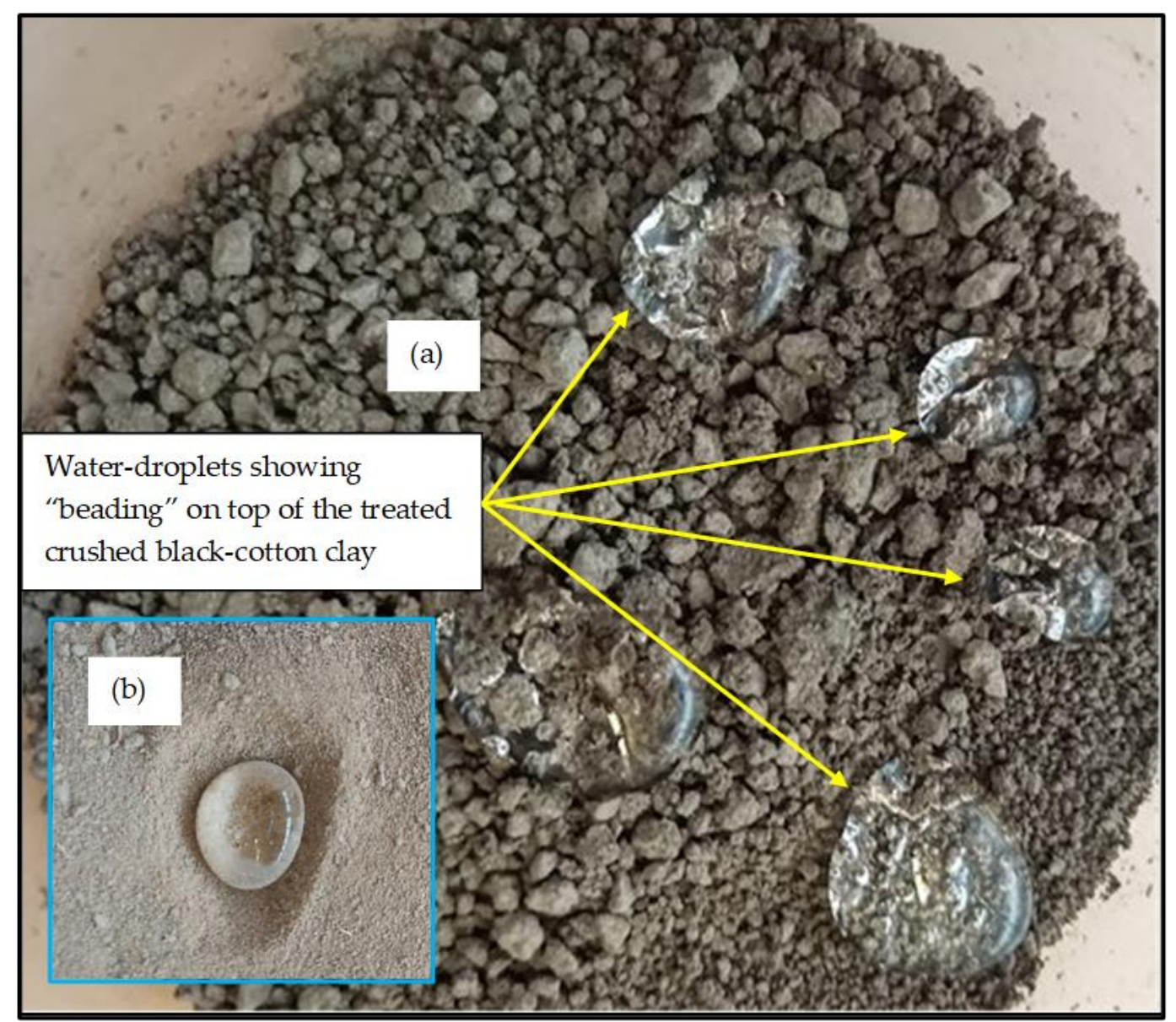

Figure 4: (a) Practical demonstration of the hydrophobic (water-repellent) surfacing created using black-cotton soil treated with a material compatible nano-silane. The hydrophobic nature of the surface of the broken clay particles prevents the water droplets shown on top of the broken treated clay particles from penetrating the material or the gaps between the broken pieces of the treated clay sample; (b) Similarly, a water-drop remains suspended on fine-grained sands treated with a material compatible nano-silane.

\subsection{Ease of use - labour-intensive friendly application of NPNS}

The NPNS is diluted into water to contain about 5 per cent NPNS as a "clear-seal" to be applied to road surfaces. Application can be done by water-truck (at a uniform rate) but is user-friendly for easy application by hand-sprayer as demonstrated in Figure 5. Due to the small particles of the clear-seal the particles penetrate the surface quickly and is dry within a maximum of 30 minutes as shown on the right, with a Marvil apparatus to measure the rate of water penetration into the surfacing. The clear-seal (NPNS diluted in water (5 per cent concentration)) is normally applied at about 1 to $2 \mathrm{l} / \mathrm{m}^{2}$ - the application rate depends on the condition of the road surface and is applied at a rate that will not result in run-off from the road surface. Clear-seals applied as a preventative measure, will require no new road markings and will not result in any pick-up and contamination. 


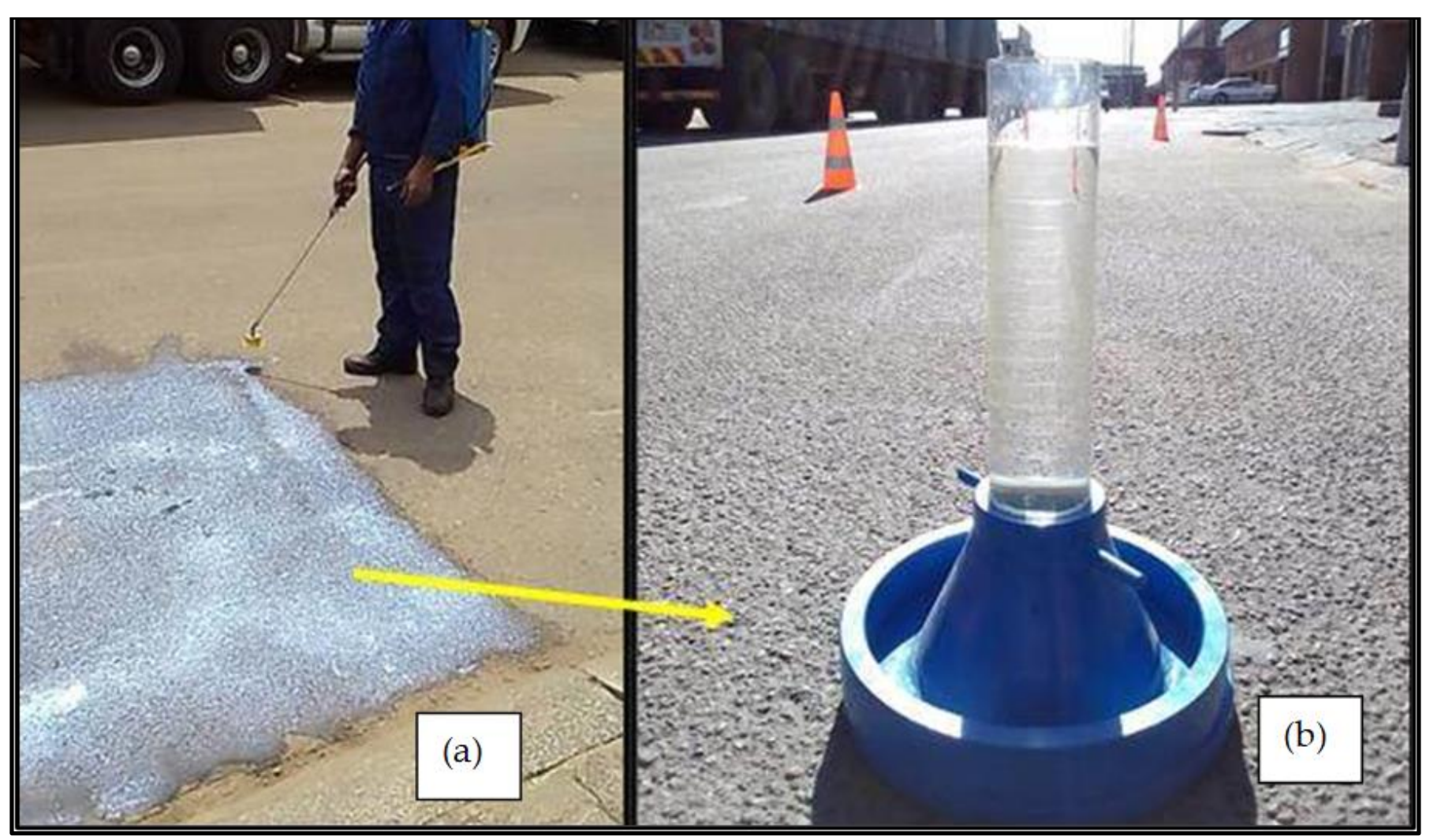

Figure 5: (a) Application of a clear-seal by hand-sprayer at a rate of approximately 1 to $21 / \mathrm{m}^{2}$ (about 5 to $10 \mathrm{ml}$ of NPNS $/ \mathrm{m}^{2}$ at a material cost of about US $\$ 0.10$ to US $0.20 / \mathrm{m}^{2}$ ) - note the close proximity of the sprayer head to the road surface to prevent loss during windy conditions; (b) the dried surfacing 30 minutes after application of the clear-seal with a Marvil apparatus placed on top of the surfacing to measure the rate of water penetration into the treated surface.

The Marvil apparatus is sealed onto the surfacing using putty to prevent the water from seeping between the surfacing and the bottom of the Marvil apparatus. The fact that the rate of application of the clear-seal should be a function of the condition of the road surface makes application by hand-sprayer the preferred method of application. With hand-application the rate of application can be adjusted based on visual observations. With more distress in certain areas of the road surface (e.g. the wheel-tracks), the rate can be controlled to prevent run-off and wastage. Application by water-bowser will, in the case of a varying in the surface condition, result in over- or under-application along a length of road.

The Marvil apparatus will be used (as shown) to measure and quantify the effect of a clear-seal application on various surfacings. Measurements were taken before the clearseal application and after the clear-seal has dried and at some time after the treated surfacing has been exposed to traffic. Worst-case scenarios have been selected to show the waterrepellent nature of a clear-seal in practice under a variation of conditions. The clear-seal product [18] (refer Acknowledgements) used, was applied by hand sprayer (refer Figure 5 ) to a very poor quality untreated compacted (laterite) material, a compacted high-quality untreated crushed-stone base-layer (granular materials without any surfacing or protective prime) and a surfacing which have been severely compromised (in terms of its protective qualities to prevent water-ingress into the base-layer), full of crocodile cracking (alligator cracking) to quantify, in practice, the impact of the clear-seal application. In cases such as that shown in Figure 5(b), where the clear-seal is applied as a preventative measure, no water penetration were measured over at set time intervals lasting in excess of 3 hours. 


\section{Nanotechnology Solutions to Road Maintenance: Protecting and/or Restoring the Integrity of Road Surfaces}

\subsection{Clear-seal applications}

As discussed, various compacted materials were treated and tested to measure and quantify the impact of the clear-seal application. In all examples, the clear-seal was applied by hand-sprayer to saturation of the material as shown in Figure 5, at a rate adjusted by eye to limit (prevent) run-off of the clear-seal and to optimise application rates.

4.2.1. Treatment of a very poor material containing more than 20 per cent Kaolinite clay at the University of Pretoria, Engineering 4 facility

A small section of this compacted material was treated to test the hydrophobic nature that can be achieved with the clear-seal [18] (refer Acknowledgement) treatment. The material consisted of a very poor quality G10 [19] clay-based material compacted to $93 \% \bmod$ AASHTO [20,21] as shown in Figure 6(a). The treated section is shown as an inset in Figure 6(a). After drying, water was poured onto the treated surface, the effect of which is shown in Figure 6(b). The beading of the water shows the high degree of hydrophobicity achieved through the treatment of the very poor material (compare Figure 3). No water-penetration tests were done on this very poor material.

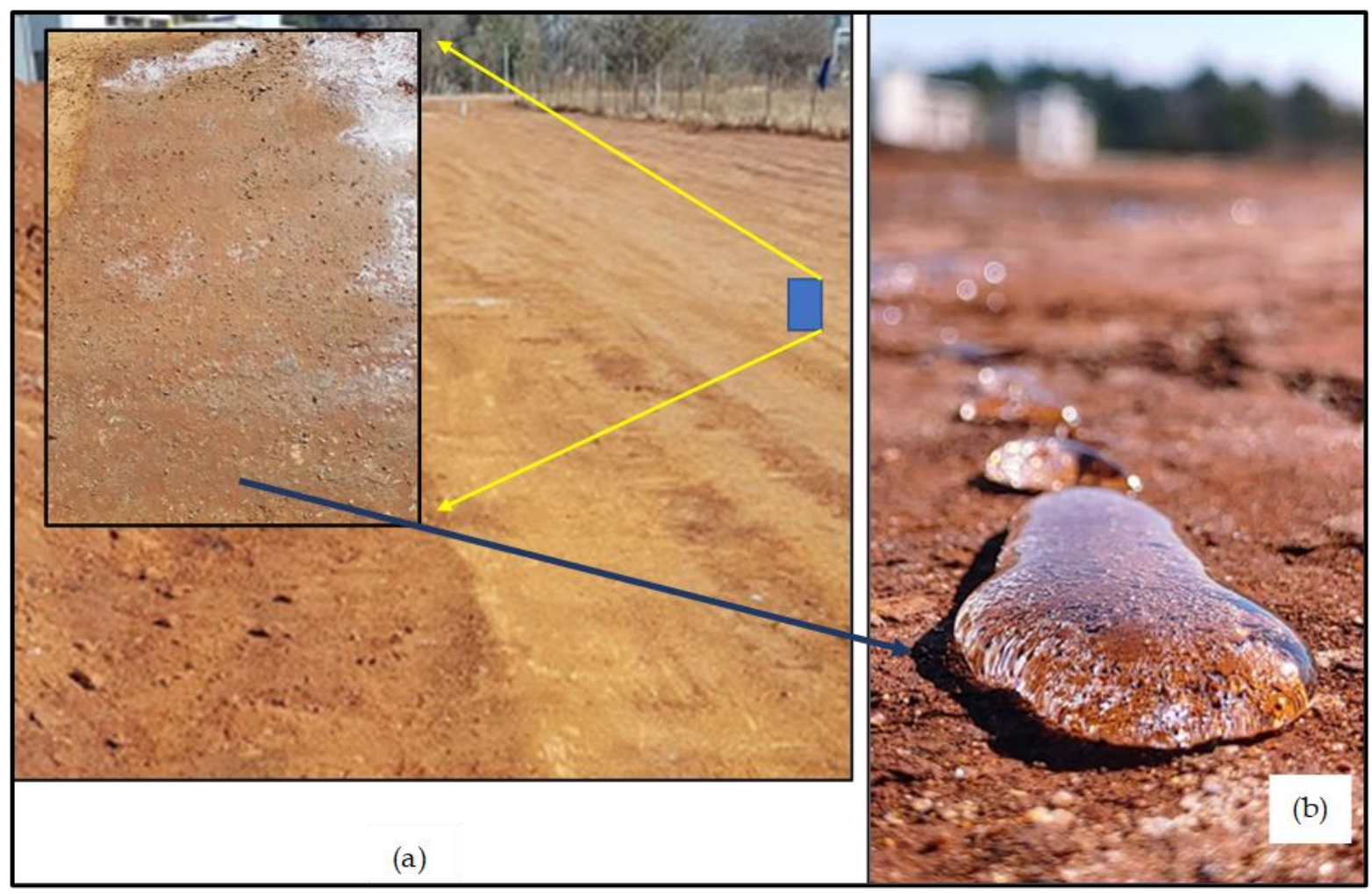

Figure 6: (a) Very poor-quality clay material (G10 quality material [19]) compacted to 93\% mod AASHTO [20,21] and hand-sprayed with a clear-seal [18] (refer Acknowledgements) until saturation; (b) After drying of the clear-seal, water was poured onto the treated section - the shape of the water drops show the level of hydrophobicity achieved on the surface of the red-clay material (refer Figure 3).

4.2.2. Treatment of a very good G1 quality [19] crushed stone base-layer that has not been primed at the University of Pretoria, Engineering 4 facility

A section of a newly constructed very good G1 quality [19] base-layer compacted to $88 \%$ of ARD [22] was not previously treated with any surfacing or prime. Consequently, the same clear-seal [18] (refer Acknowledgments), as applied on the red-clay material shown in Figure 6, was applied by hand-spay to saturation on the expose base-layer. The clear-seal [18] (refer Acknowledgements) was applied at a materials cost of approximately 
US\$ 0.08 to US\$ $0.12 / \mathrm{m}^{2}$ to visually assess and to test and quantify the effect of the clearseal application using the Marvil apparatus. Shortly after application of the protective clear-seal, $5 \mathrm{~mm}$ of rain fell at the site and the protective impact wat tested through the turning of a truck over the treated and untreated G1quality [19] base-layer, the effect of which is shown in Figure 7.

Nine months after application, the Marvil apparatus was used on the G1 quality [19] layer to test the rate of penetration of the water into the G1 [19] layer. Tests were performed on an untreated section of the G1 [19] base, on a section of the G1 [19] base that was treated with the clear-seal [18], but not subjected to any traffic and on a section treated with the clear-seal [18], subjected to light vehicle traffic over the nine-month period. The conditions of the G1 quality [19] crushed-stone base-layer test sections after a period of 9 months are shown in Figure 8. The penetration rates of the G1 layer after being exposed to elements for more than 9 months with some vehicle movement on some sections are summarized in Table 1. It should be noted that the period covered spanned the 2020/21 summer rain-fall season - an unusually good season in terms of the rain recorded. The water damage from the rain on the exposed G1 [19] base layer with no application of the clear-seal, can be seen if Figure 8 (aa). The corresponding conditions of the G1 [19] test sections (where the Marvil tests were done) after cleaning the surfacing from any loose material through light brushing with a hand brush, are shown in Figure 9.

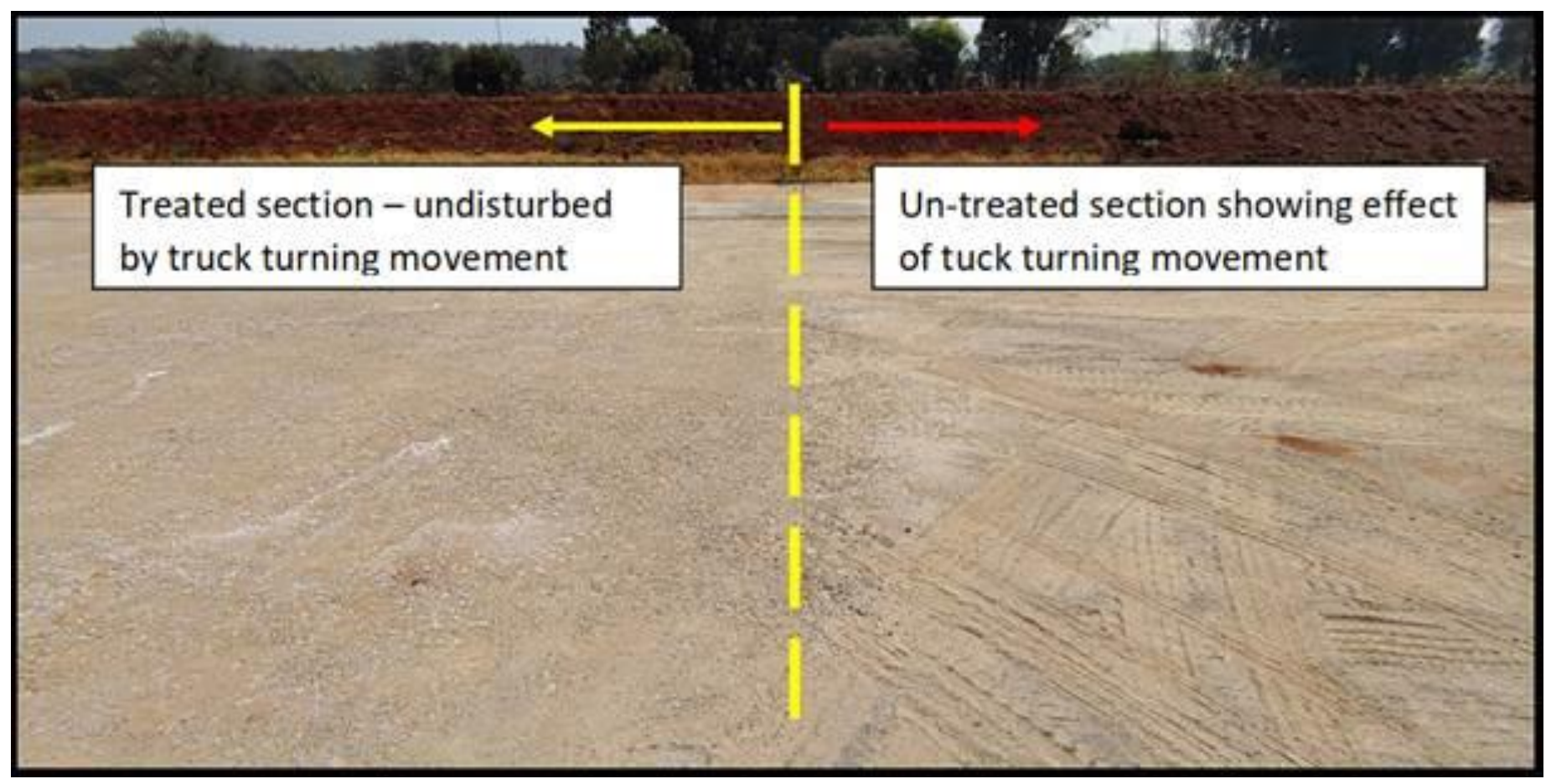

Figure 7: NPNS clear-seal application on an unprotected G1 quality [19] base-layer at the Engineering 4 facility at the University of Pretoria, showing the effect of truck turning movements on sections treated with the clear seal [18] (left) versus untreated section (right) - the application was done by hand-sprayer to saturation. 


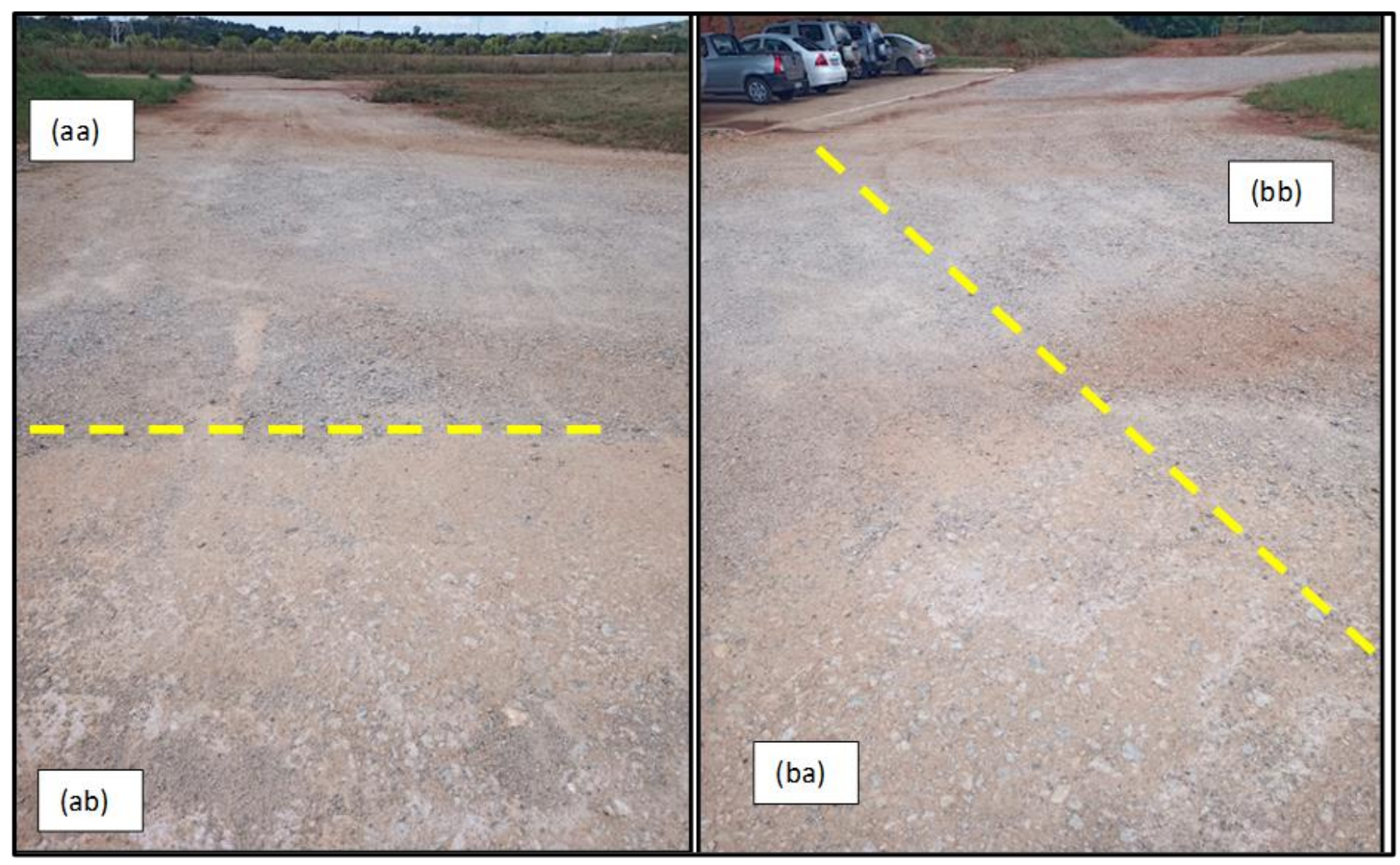

Figure 8: Condition of the G1 quality[19] base-layer at the University of Pretoria, Engineering 4 facility after being open for 9 months from 21/8/2020 to 20/5/2021: (aa) Un-treated G1 layer subjected to rain; (ab) Clear-seal [18] treated subjected to rain; (ba) Clear-seal [18] treated subjected to rain; (bb) Clear-seal treated subjected to rain and light traffic.

Table 1: Penetration rates tested using Marvil apparatus of the application of a NPNS clear-seal [18]* on an exposed G1 quality [19] base-layer at the Engineering 4 facility at the University of Pretoria (date applied - 21-08-2020; date tested $-20-05-2021$ ) - test duration on each section $=1$ hour.

\begin{tabular}{|c|c|c|c|}
\hline $\begin{array}{l}\text { Permeability measured on } \\
\text { the G1 quality [19] base- } \\
\text { layer per volume of water }\end{array}$ & $\begin{array}{l}\text { G1 quality [19] } \\
\text { base- layer - Un- } \\
\text { treated } \\
\text { (Figure } 8(a) \text { ) }\end{array}$ & $\begin{array}{l}\text { G1 [19] layer - } \\
\text { Treated with a NPNS } \\
\text { clear-seal [18] ap- } \\
\text { plied at } \pm 1 \mathrm{l} / \mathrm{m}^{2}-\text { no } \\
\text { traffic (Figure } 8(b)\end{array}$ & $\begin{array}{l}\text { G1 [19] layer - Treated with a NPNS } \\
\text { clear-seal [18] applied at } \pm 1 \mathrm{l} / \mathrm{m}^{2}- \\
\text { with } 9 \text { months of light vehicle trav- } \\
\text { elling and some surface damage } \\
\text { (Figure } 8(\mathrm{c}) \text { ) }\end{array}$ \\
\hline @ 50 ml & $0.370 \mathrm{l} /$ hour & $0.035 \mathrm{l} /$ hour & $0.059 \mathrm{l} /$ hour \\
\hline @ 100 ml & $0.260 \mathrm{l} /$ hour & - & - \\
\hline @ 150 ml & $0.207 \mathrm{l} /$ hour & - & - \\
\hline
\end{tabular}

\section{Permeability at different}

intervals

\begin{tabular}{llll}
\hline $\mathbf{2 0} \mathrm{ml}$ & - & $0.030 \mathrm{l} / \mathrm{hour}$ & - \\
\hline $\mathbf{2 5} \mathrm{ml}$ & - & - & $0.061 \mathrm{l} / \mathrm{hour}$ \\
\hline $\mathbf{7 5} \mathrm{ml}$ & $0.279 \mathrm{l} /$ hour & - & \\
\hline Average Permeability & $0.279 \mathrm{l} /$ hour & $0.030 \mathrm{l} / \mathrm{hour}$ & $0.061 \mathrm{l} / \mathrm{hour}$ \\
\hline
\end{tabular}

*(refer Acknowledgements) 


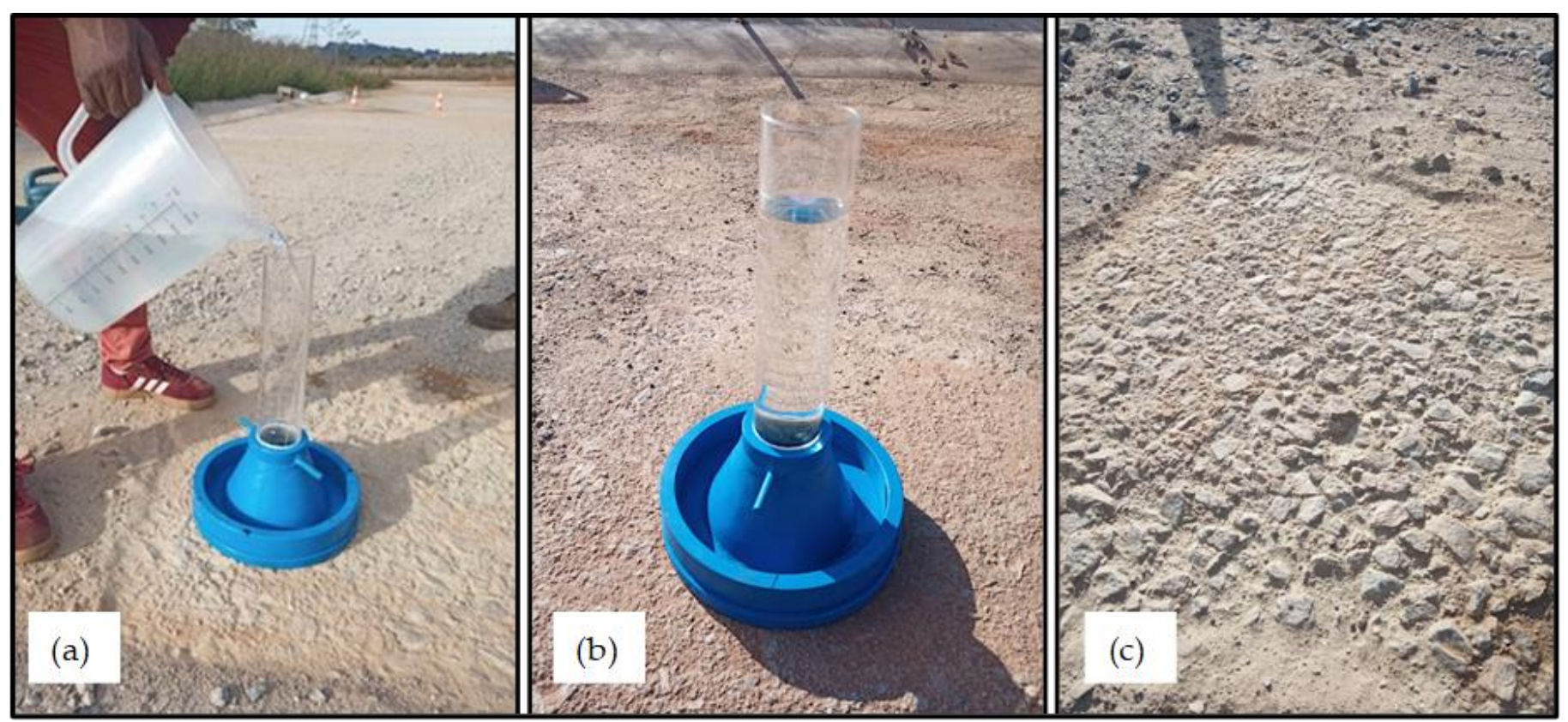

Figure 9: (a) Condition of G1 [19] unprotected surfacing subjected to 9 months of rain in 2020/21 Pretoria South Africa (loosened material brushed clean); (b) G1[19] base-layer with clear-seal [18] applied after 9 months of rain in 2020/21 and no traffic; (c) Cleanly brushed surfacing of G1 [19] base-layer treated with a clear-seal [18] subjected to 9 months of rain and light traffic.

The effect of the clear seal [18] as measured in Table 1 and the corresponding photographs in Figure 9 are conclusive. The clear-seal application [18] protected the G1 quality [19] crushed stone base-layer over a period of 9 months without any surface damage and reduced the water-ingress by a factor of 10 . Although the surfacing experienced some damage under the action of light traffic over a period of 9 months (Figure 9(c)), the baselayer still retained considerable resistance to water-ingress, which is still one-fifth of that of the untreated G1 [19] base-layer section. This G1 [19] base-layer subjected to light traffic over a period of 9 months clearly shows the depth of protection provided by the clear-seal [18] application.

4.2.3. Treatment of road section with some severe crocodile cracking (alligator cracking) in the wheel-tracks

Similar to the measurements on the G1 quality [19] base-layer, the effect of an application on a clear-seal [18] (diluted NPNS) was shown on a severely compromised surfacing exhibiting severe crocodile cracks (alligator cracks). The condition of the surface with the Marvil apparatus is shown in Figure 10(a) before any treatment. Water is clearly seeing seeping out underneath the Marvil apparatus trough the extensive network of crocodile cracking (alligator racking). After application of a clear-seal [18] to a rate to saturation and the drying thereof, another Marvil test was done close to the original test site (refer comparative test sections clearly visible in Figure 10(b)). After the clear-seal [18] application no water could be observed in the cracks leaving from the Marvil apparatus.

Water penetration using the Marvil apparatus was measured both before and after the application as recorded at different time intervals as given in Table 2. Table 2 also contains comparative measurement taken after a period of 14 days during which time the road was opened to normal traffic. The reduction in water-penetration into the severely cracked surface is clearly evident. After application of the clear-seal the water ingress into the pavement structure was reduced by 97 per cent. After 14 days of the road being opened to traffic, the water-ingress was still reduced by 81 per cent. These results are significant and in combination with as hydrophobic cost-effective slurry mix, could restore the integrity of the surfacing for a number of years. 


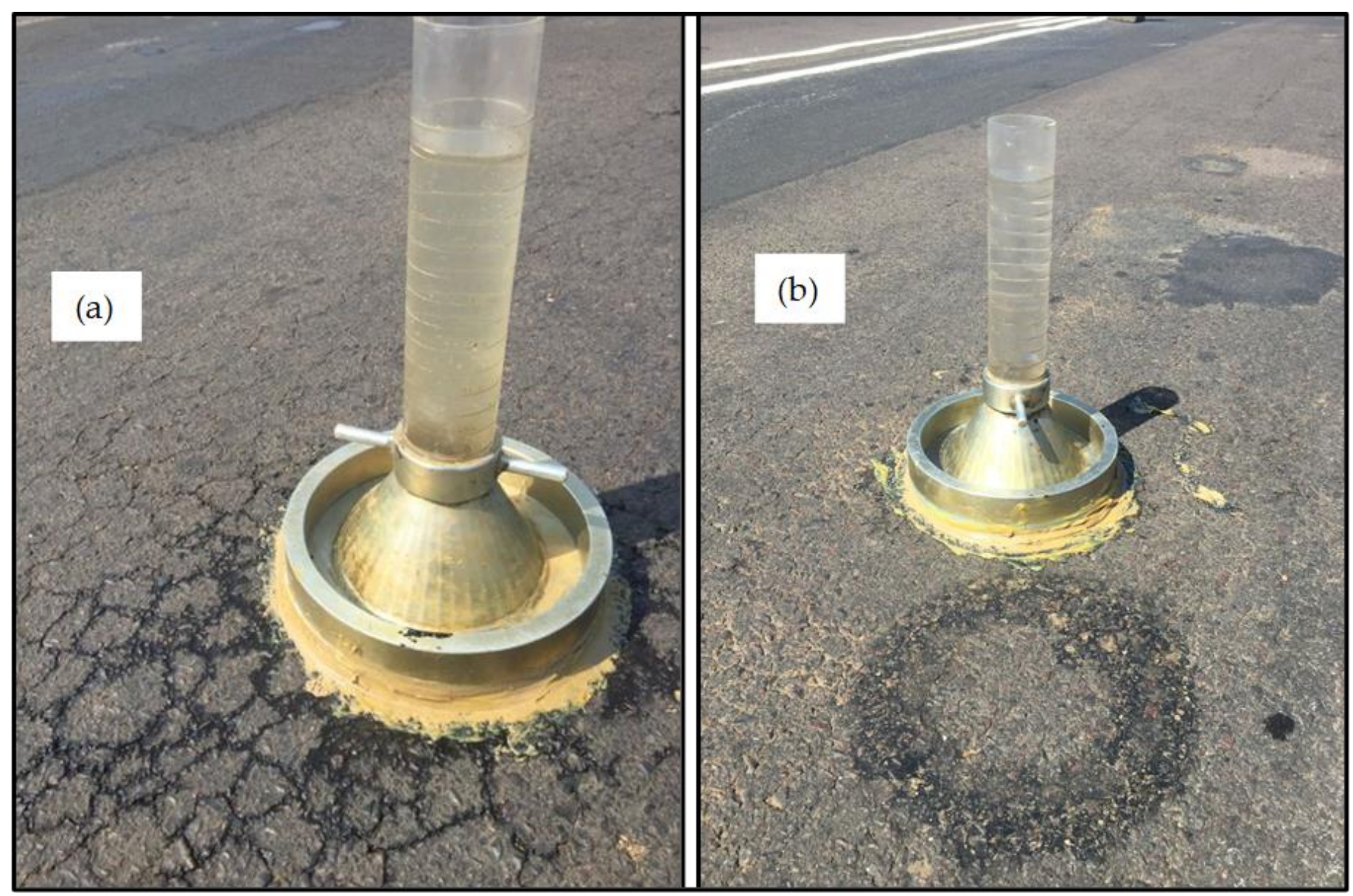

Figure 10: (a) Water-penetration before application of a clear-seal, showing water seeping out along the extensive network of cracks; (b) Marvil test after application of a clear-seal showing the sealing effect of the clear-seal [18] (refer Acknowledgements).

Table 2: Penetration rates tested using the Marvil apparatus of the application of a clear-seal [18] on a severely cracked surfacing exhibiting closely spaced crocodile cracking (refer Acknowledgements).

$\begin{array}{lll}\text { Pre-treated } & \text { After application of } & \text { 14 days after application of } \\ \text { (Figure 8(a)) } & \begin{array}{l}\text { a clear-seal } \\ \text { (Figure 8(b) }\end{array} & \begin{array}{l}\text { clear-seal and opened to } \\ \text { traffic }\end{array}\end{array}$

\begin{tabular}{|c|c|c|c|}
\hline \multicolumn{4}{|c|}{ Permeability at different intervals } \\
\hline 7 minutes & $0.214 \mathrm{l} /$ hour & $0.000 \mathrm{l} /$ hour & $0.017 \mathrm{l} /$ hour \\
\hline 15 minutes & $0.200 \mathrm{l} /$ hour & $0.008 \mathrm{l} /$ hour & $0.020 \mathrm{l} /$ hour \\
\hline 20 minutes & $0.150 \mathrm{l} /$ hour & $0.009 \mathrm{l} /$ hour & $0.018 \mathrm{l} /$ hour \\
\hline Average Permeability & $0.188 \mathrm{I} /$ hour & $0.006 \mathrm{I} /$ hour & $0.036 \mathrm{l} /$ hour \\
\hline
\end{tabular}

In order to address any concerns about a possible decrease of the skid-resistance of the surfacing caused by the application of the clear-seal, skid resistance testing was done using the British Pendulum Tester (Figure 11), both before and after the application of the clear-seal. The results of the skid-resistant tests are given in Table 3. No statistical difference between the test done before and after the application of the clear-seal was measured. 


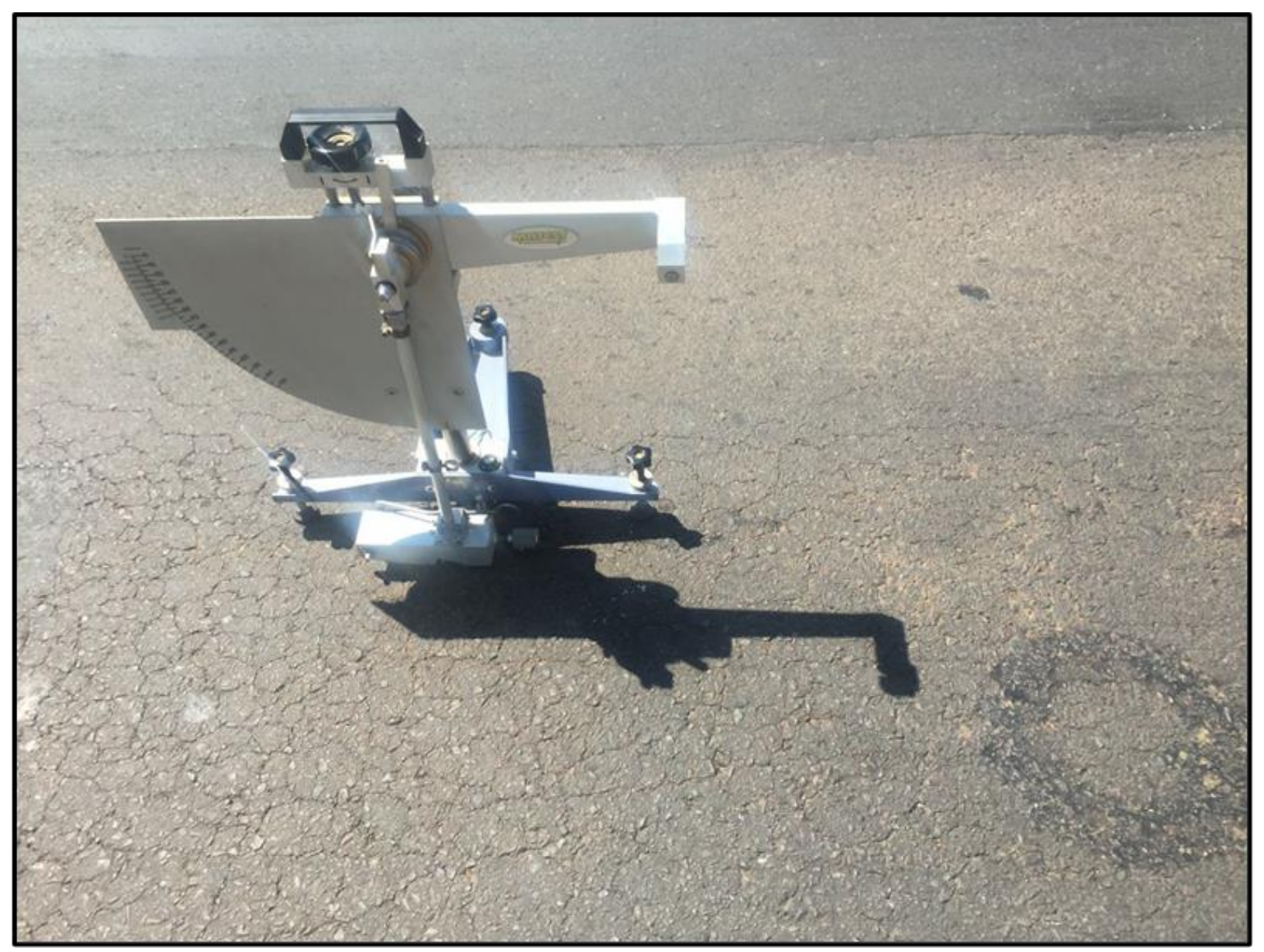

Figure 11: Skid resistance testing done before and after application of a clear-seal [18] (refer Acknowledgements).

Table 3: Skid-resistance measurements busing the British Pendulum testing device before and after the application of the clear-seal [23] (refer Acknowledgements).

\begin{tabular}{lll}
\hline Pendulum Test Results & Control (No Seal) & With clear-seal application \\
\hline Test Point 1 & 100 & 110 \\
\hline Test Point 2 & 110 & 100 \\
\hline Test Point 3 & 110 & 95 \\
\hline Test Point 4 & 90 & 100 \\
\hline Test Point 5 & 95 & 90 \\
\hline Total (Average) & $\mathbf{1 0 1}$ & $\mathbf{9 9}$ \\
\hline
\end{tabular}

\subsection{Repair of potholes using pre-prepared NME pothole kits}

In cases where damaged in terms of potholes have already occurred, the surfacing can quickly be fixed with an anionic NME [23] (refer Acknowledgements) gravel mix (Figure 12). Due to the organofunctional modification of the anionic NME mix, the pothole mix will dry within an hour. The use of an anionic NME pot-hole mix [23] is done at a fraction of the costs of traditional cold-mix, providing a hydrophobic (water-repellent) restored surfacing. The tested Unconfined Compressive Strengths (UCS) and the Indirect Tensile Strengths (ITS) done according to the recommended rapid curing process in a dry and wet state [16], are shown in Table 4. Before the repair of potholes, the hole should first be cleaned of any loose material as per normal procedure. The pothole must be dry and for potholes requiring more than one bag to fill, the exposed material within the pothole should be treated with the application of a clear seal (diluted NPNS) or by "painting" the cleaned pothole with some spare anionic NME binder. 


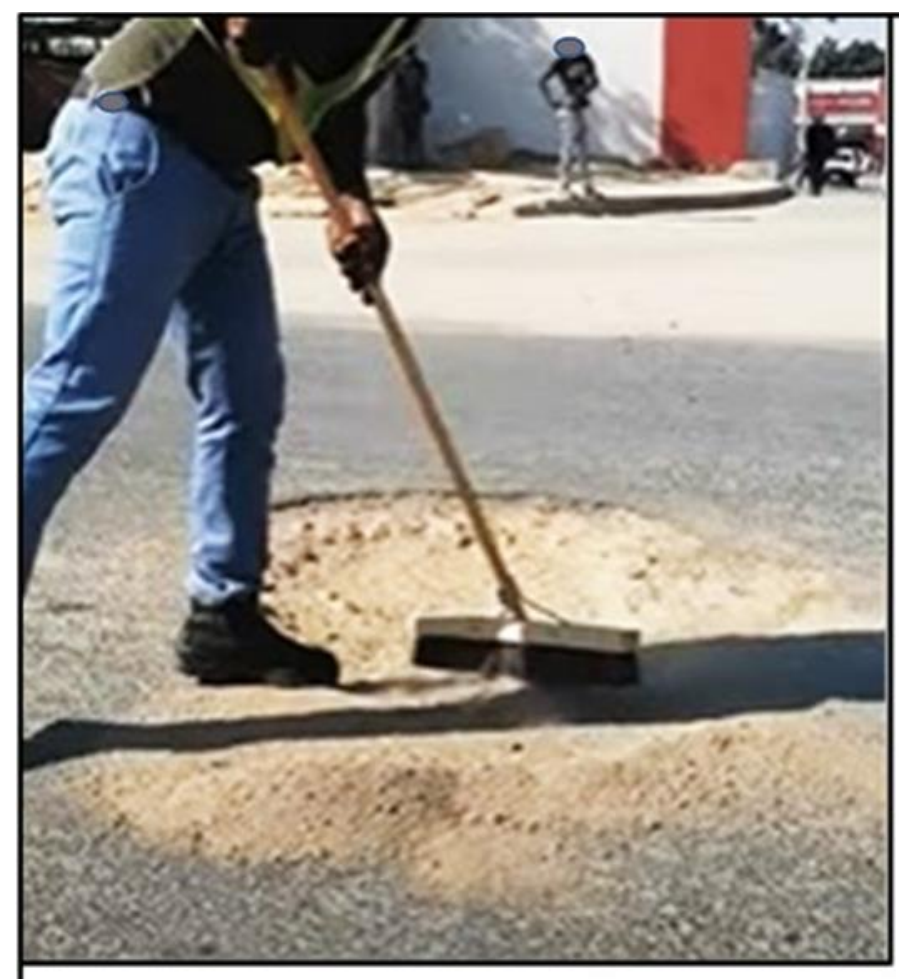

(a)

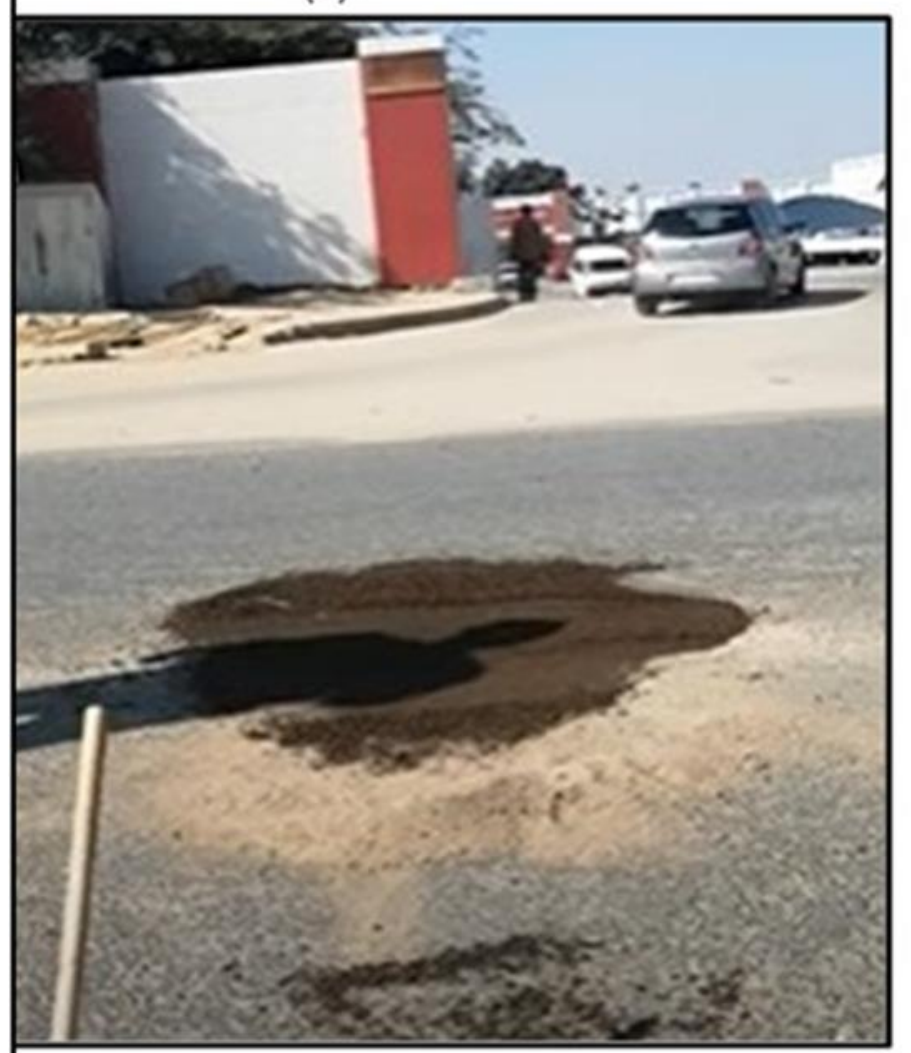

(c)

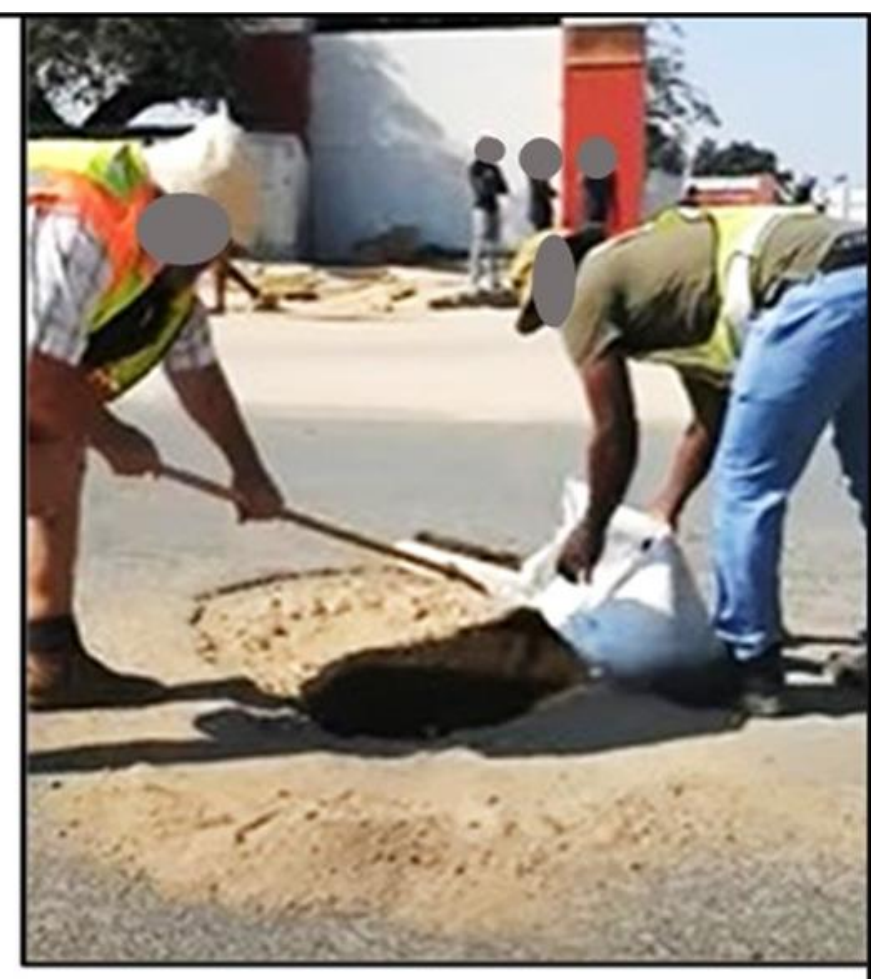

(b)

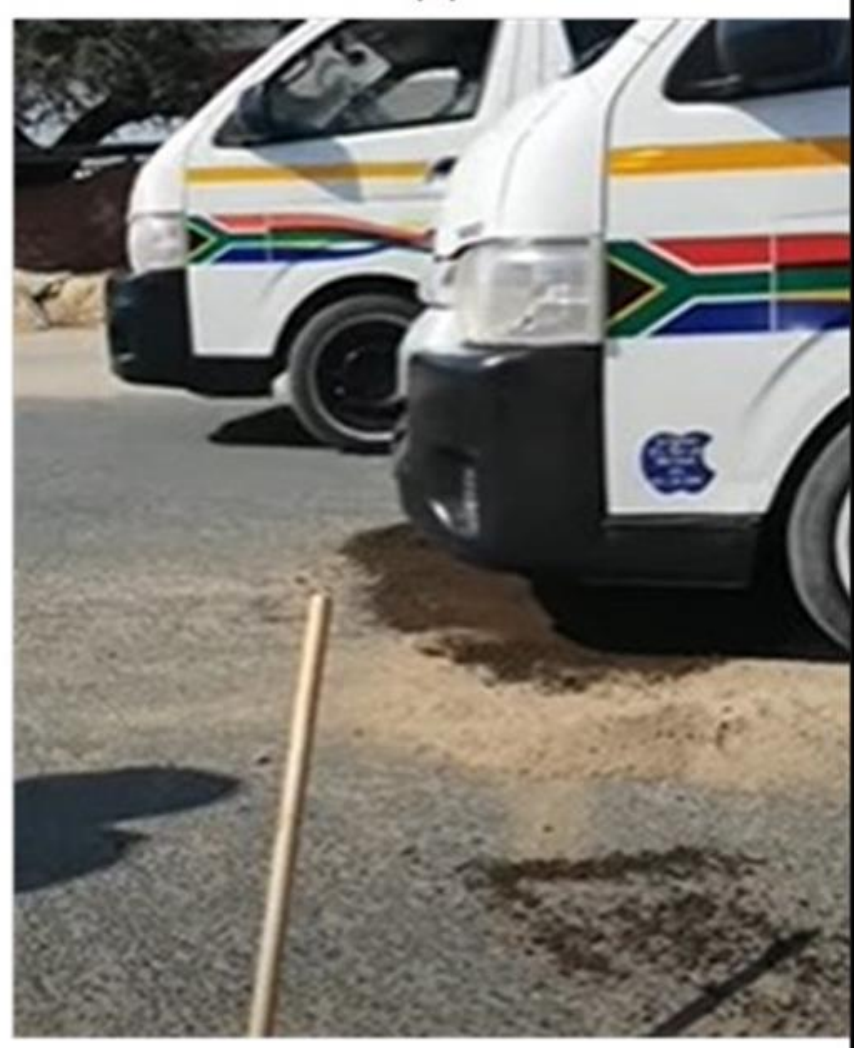

(d)

Figure 12: (a) Cleaning of pothole; (b) filling pothole with a water-resistant anionic NME gravel [23] (refer Acknowledgements); (c) hot-hole filled and partially compacted by hand, and (d) vehicles driving over filled pothole and increase compaction. 
Table 4: Unconfined Compressive Strength (UCS) and Indirect Tensile Strength (ITS) tests performed on a NME binder prepared pothole repair kit [23] (refer Acknowledgements) - evaluated against the criteria used to evaluate the stabilisation of material using a material compatible NME stabilising agent [16].

\begin{tabular}{llllll}
\hline UCS (MPa) & & $\begin{array}{l}\text { Material } \\
\text { Classification [16] }\end{array}$ & ITS (kPa) & & $\begin{array}{l}\text { Material } \\
\text { Classification [16] }\end{array}$ \\
\hline UCS (dry) & 4.4 & NME1 & ITS (dry) & 350 & NME1 \\
\hline UCS (wet) & 4.3 & NME1 & ITS (wet) & 320 & NME1 \\
\hline RCS & $98 \%$ & NME1 & RTS** & $91 \%$ & NME1 \\
\hline \multicolumn{2}{r}{ RCS = Retained Compressive Strength [16]; ${ }^{* *}$ RTS = Retained Tensile Strength [16] }
\end{tabular}

The formation of potholes is usually an indication of a severely compromised surfacing in terms of its ability to prevent water from entering the pavement structure. It follows, that the fixing of individual potholes will not be a solution to restore the integrity of the surfacing and pot-holes will continue to develop along the length and width of the road. In order to restore the integrity of a road surface, the filling of potholes should be done as one element in a process to repair and restore the integrity of the surfacing and prevent water ingress into the base-later and the continued formation of potholes.

As per the standard in the industry, anionic NME binder pothole kits [23] (refer Acknowledgements) used in this demonstration and tests are prepared in $25 \mathrm{~kg}$ bags for ease of use on site. Due to the low viscosity of the binder, no problems of application at temperatures above freezing is experienced. These anionic NME binder pothole kits can be produced at a cost of about US\$3.00/25 kg (including packaging) at an established place of manufacturing.

The material must be compacted using normal hand compactors, or alternatively, vehicles can be used to effectively compact the material and fill the pothole to the level of the original surface. The road can be opened to traffic immediately following the filling and compaction of the pothole, as shown in Figure 12(d). The anionic NME pothole binders are designed to bind firmly with the exposed granular materials and handling by hand will cause minimum contamination with little or no bitumen sticking to exposed skin as demonstrated in Figure 13 - showing a hand (clean from any bitumen sticking to the skin and a little bit of dirt which can be cleaned with ordinary soap and water) that was purposely used to handle some material from the pothole kit to demonstrate the effect of the organofunctional modification of the bitumen emulsion used to prepare the pothole kits (as discussed in Section 3.1).

4.3. Resurfacing using a labour-intensive slurry-seal prepared using a hydrophobic anionic NME binder

It is unfortunately the experience that numerous roads in various municipalities and regions all over the world have deteriorated due to a lack of maintenance to a condition requiring at least some improvement within the wheel-tracks. A cracked surface similar to that shown in Figure 10(a), is at a point where severe pumping of fines under the action of water and traffic will develop, with associated increase in deformation, reduced riding quality and the development of potholes. In the presence of extensive existing crocodile cracking (alligator racking) and/or pothole filling, the application of a clear-seal (diluted NPNS) and anionic NME binder pothole filling, should be followed by the application of a labour-intensive anionic medium NME slurry. Such a reseal can provide some restoration of riding quality, providing a hydrophobic, maintenance free flexible, ultra-violet (UV) resistant, new surfacing with an expected surfacing life in the order off at least 5 to 10 years, (or longer) depending on traffic and climatic conditions. 


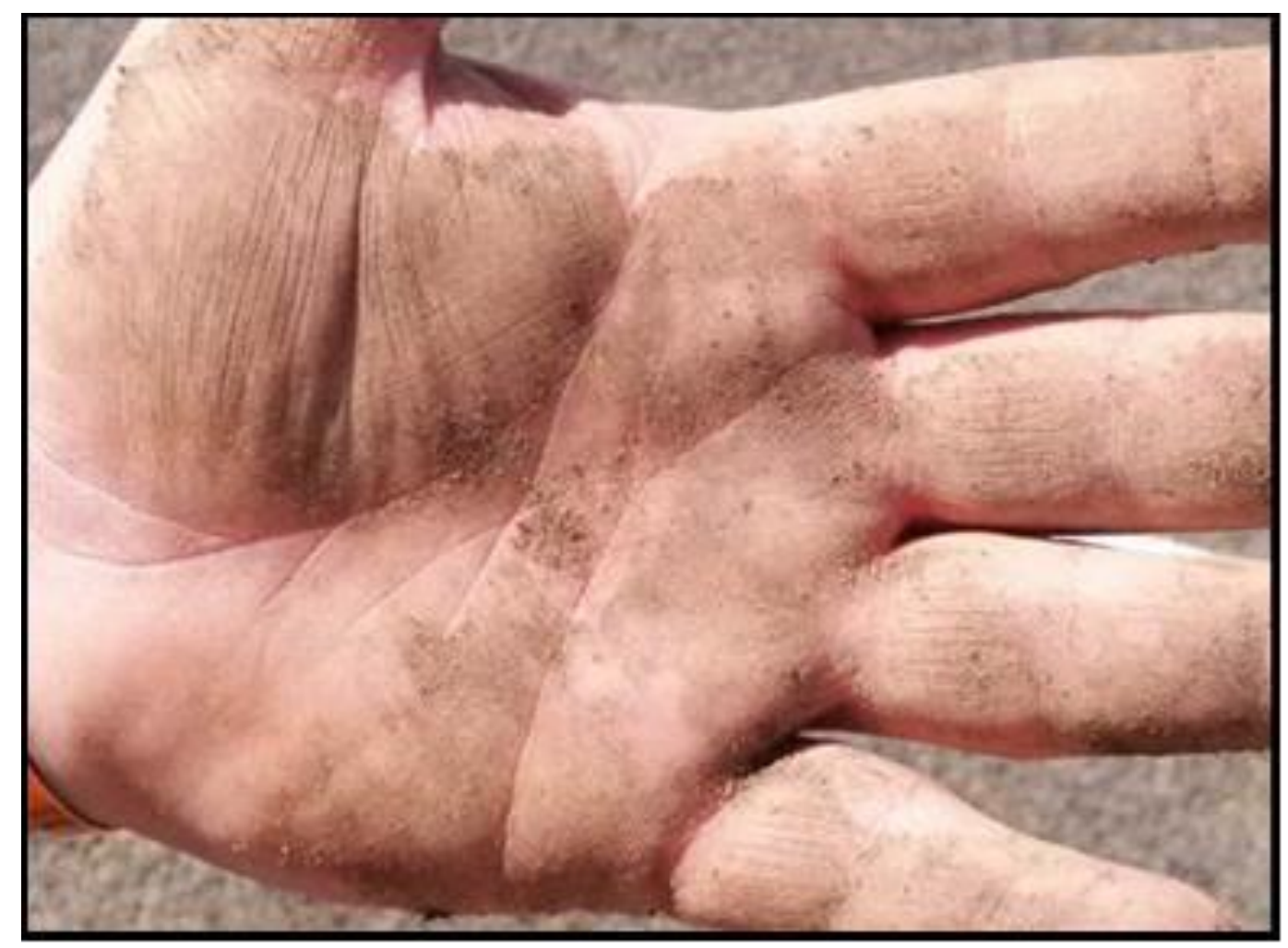

Figure 13: Demonstration of the effect of the organofunctional modification of the anionic bitumen emulsion used in the NME pothole kits that is designed to adhere to granular material, resulting in a minimum contamination when in contact with bare skin. No bitumen is sticking to the hand and the dirt can easily be washed using normal soap and water.

Slurry resealing using anionic NME binders can be done fully trough labour-intensive methods as shown in Figure 14. The anionic NME slurry mix can be prepared at a central plant in close proximity to the site in a large concrete mixer and delivered to site as shown in Figure 15. Alternatively, the anionic NME slurry can be prepared using labour-intensively methods, with small concrete mixers next to the road as shown in Figure 16, for application shown in Figure 14 and Figure 17. Figure 17 also shows the labourintensive application of an anionic NME slurry mix to a single seal to construct an anionic modified binder Cape seal [12]. In all cases, final spreading and completion of the anionic NME slurry is done by hand using squeegees for dissipating the slurry and a drag hessianmat for final texture. In cases where some substantial repairs are required in the wheel tracks, the final seal can be preceded by rut-depth deformation filling as shown in Figure 18.

With little layout, numerous employment opportunities can be created which will provide effective protection to existing surfaced roads from the detrimental effect of water-ingress and the resultant formation of potholes. These activities can effectively contribute to the protection of existing surfaced roads and positively address some of the well-documented, existing back-logs, in the maintenance of surfaced road networks. 


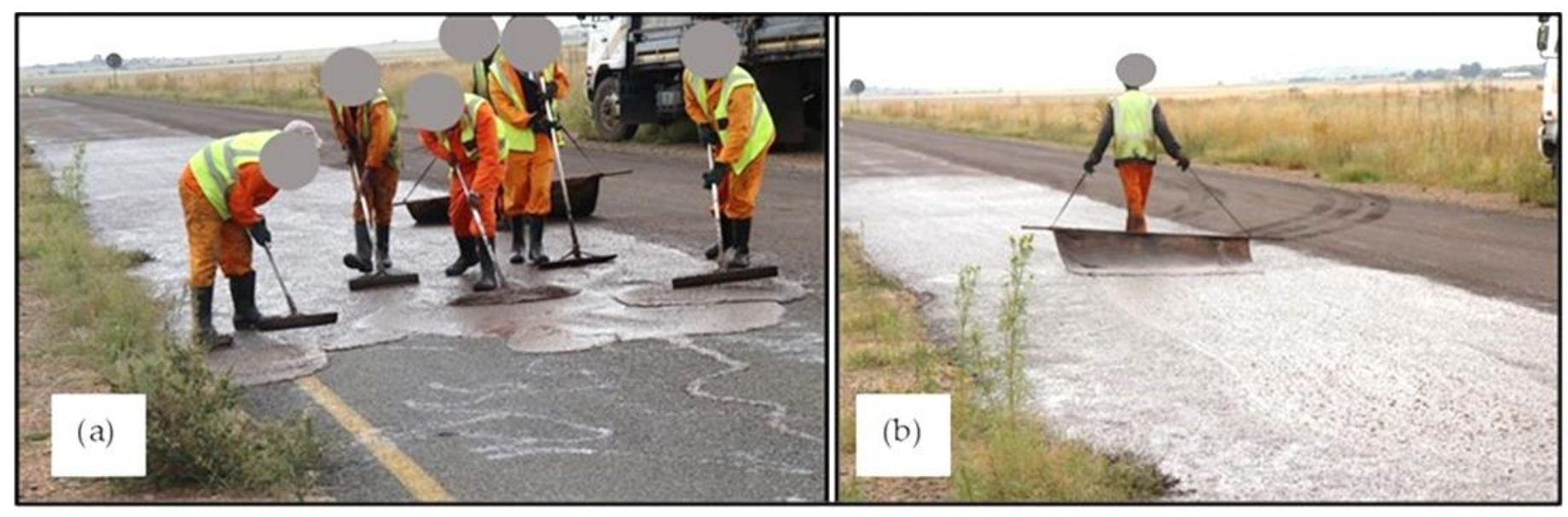

Figure 14: Application of a labour-intensive anionic NME slurry seal to effectively provide a water-repellent new surfacing, preventing water-ingress into the pavement structure on a severely cracked surfacing without disturbing the existing surfacing and restoring some riding quality - this surfacing will dry within 6 hours due to the water-repellent addition of the nano-silane - the anionic NME modified binder slurry seal is mixed to provide a six hour working envelope, found to be practical on actual projects, while creating a permanent bonding to the old surfacing and a waterresistant surfacing.

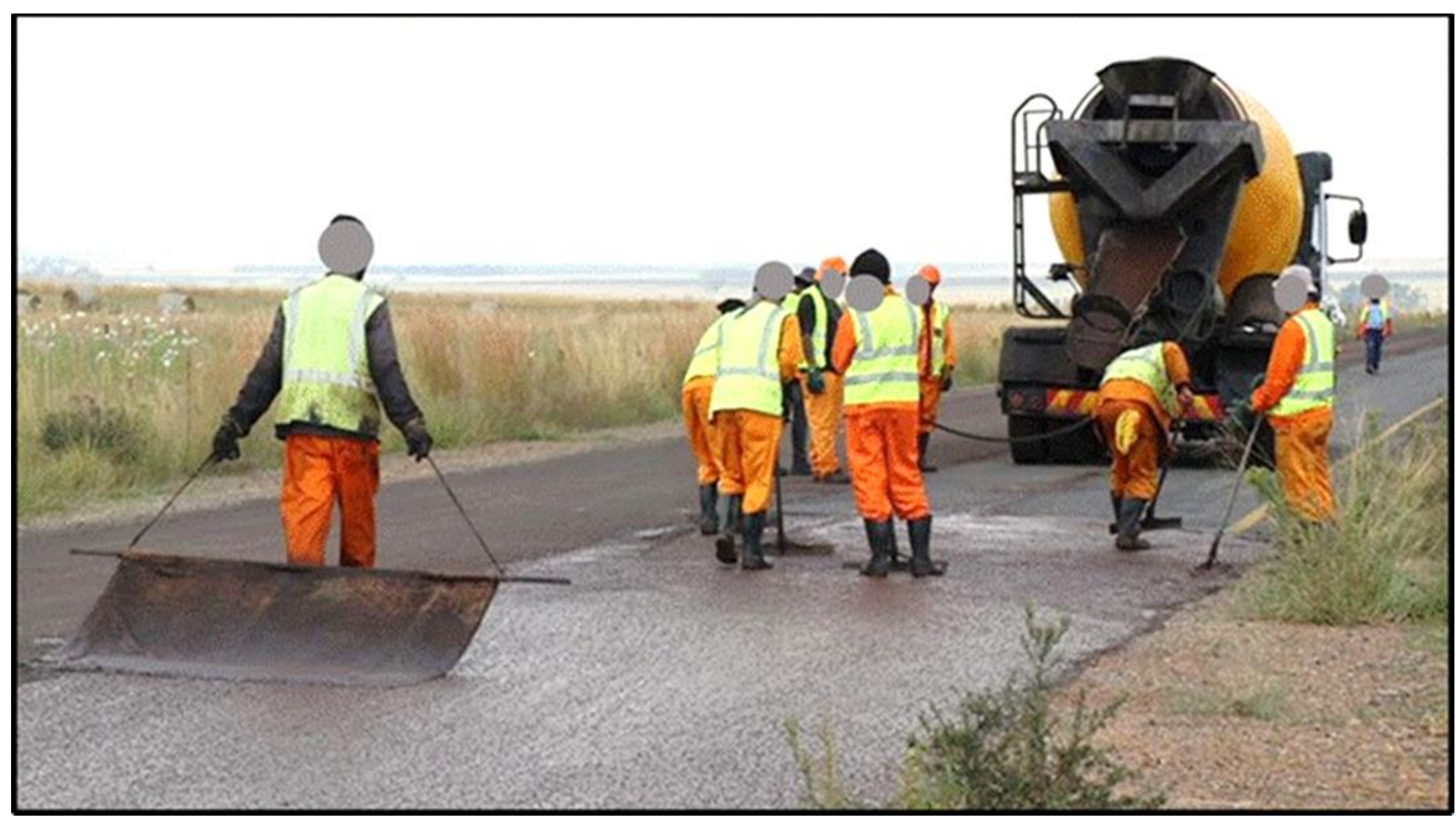

Figure 15: Slurry NME mix supplied to site using a large concrete mixer - spread using hand operated squeegees and obtaining the required texture with a hessian-mat dragged by hand. 

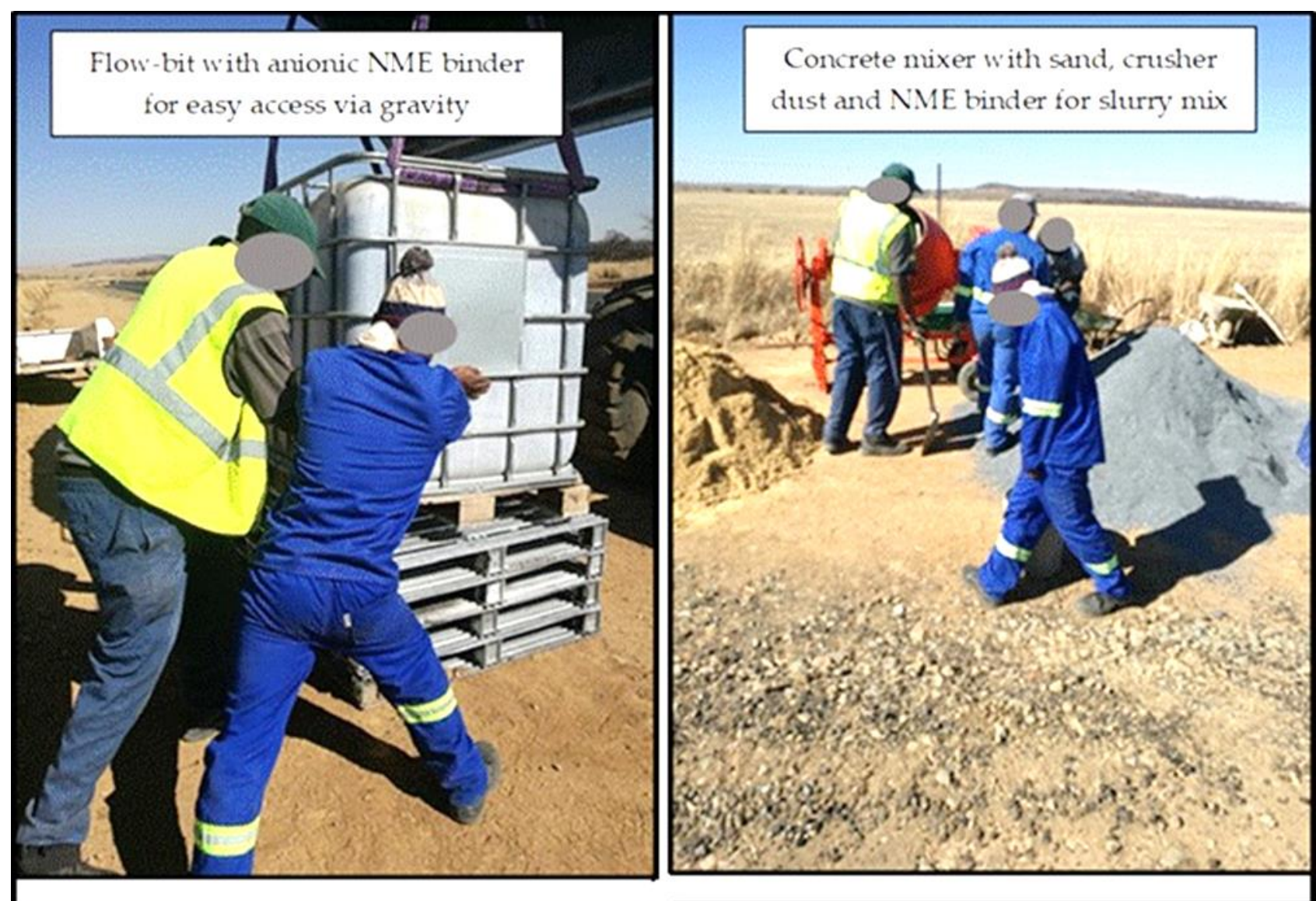

Pouring of slurry with NME binder into wheelbarrow
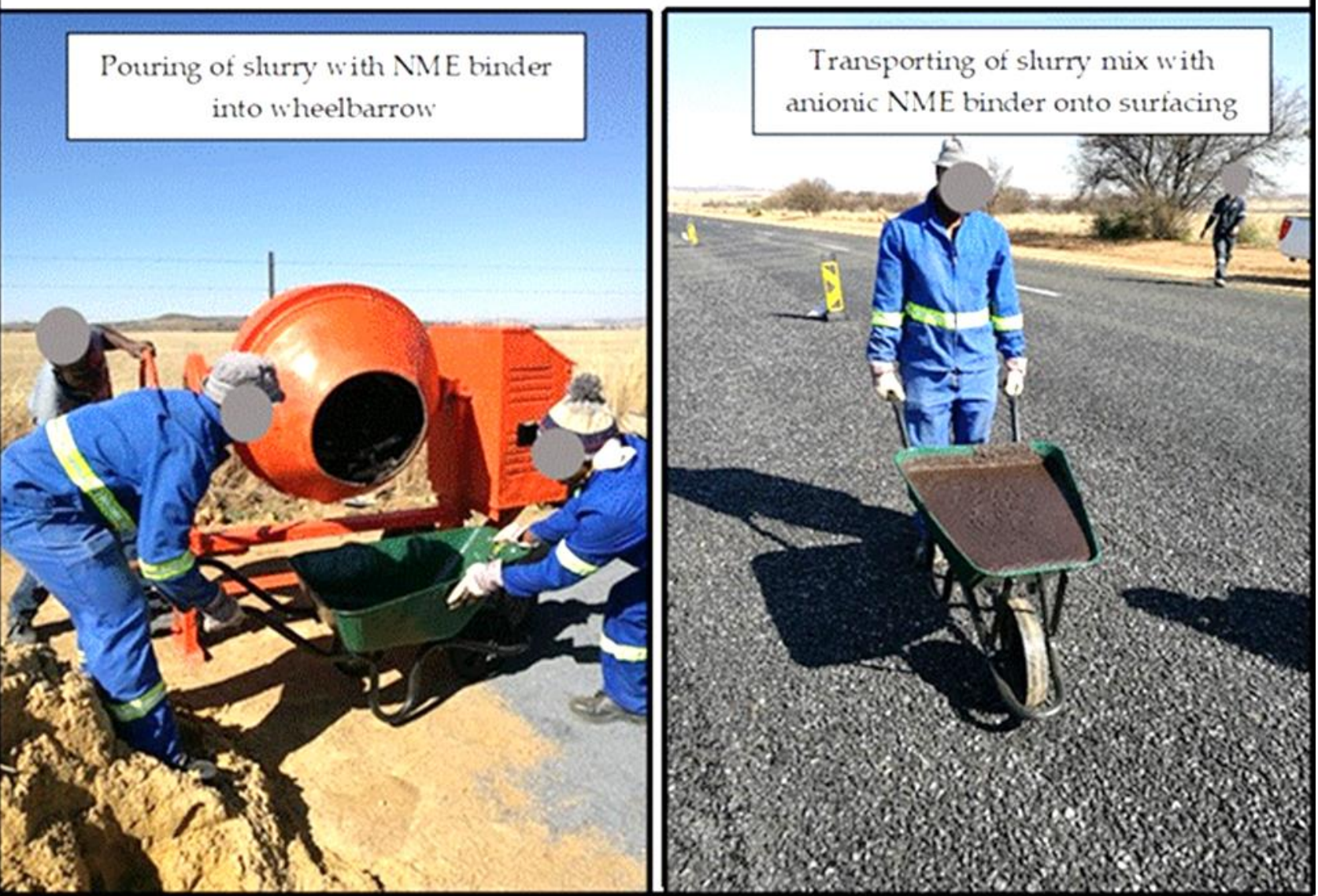

Figure 16: Labour-intensive road-side manufacturing of the slurry mix for an anionic NME binder slurry seal or for a modified Cape seal using an anionic NME binder. 


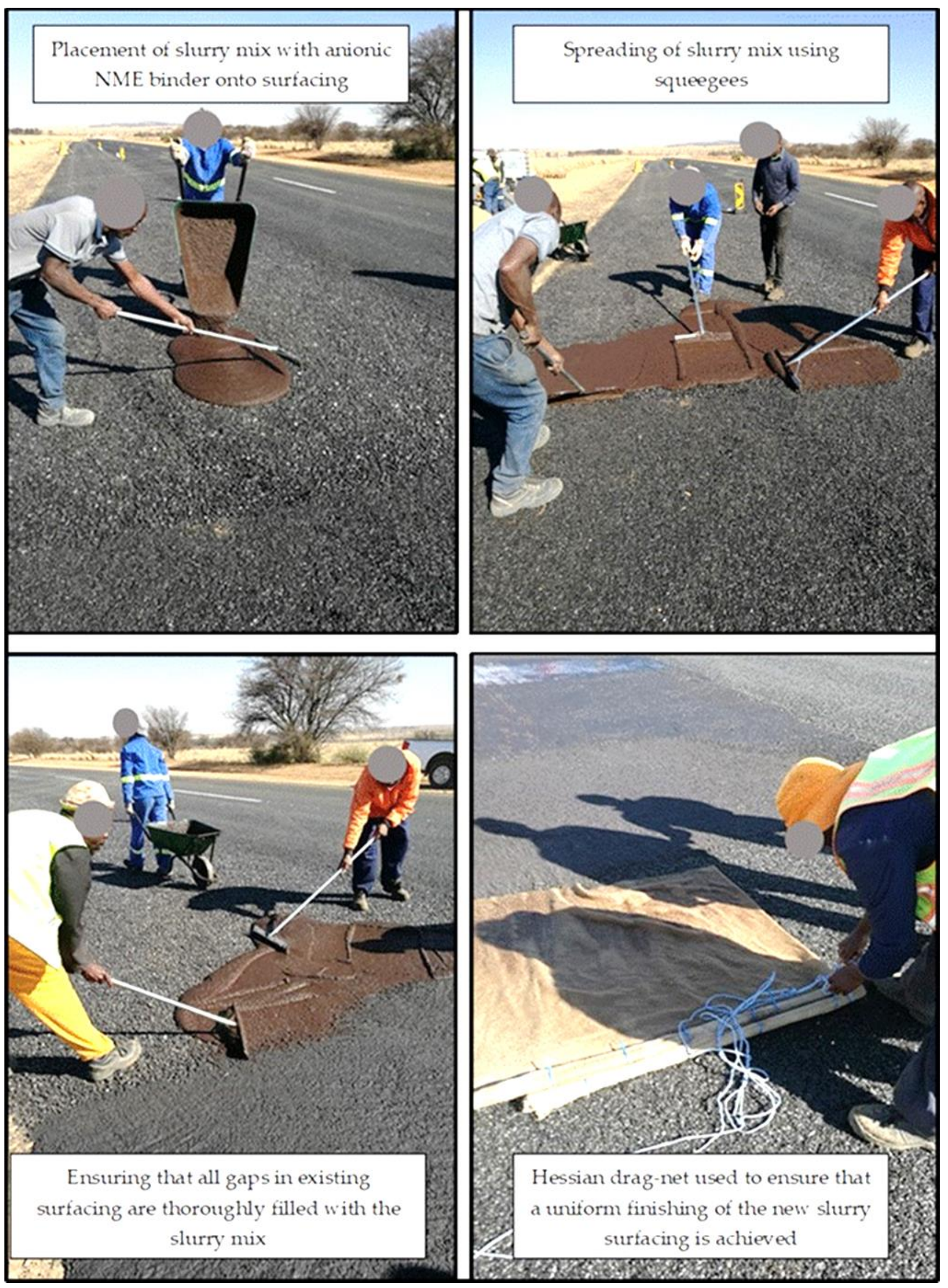

Figure 17: Labour-intensive construction of a modified Cape seal using an anionic NME binder slurry mixed on site next to the road 


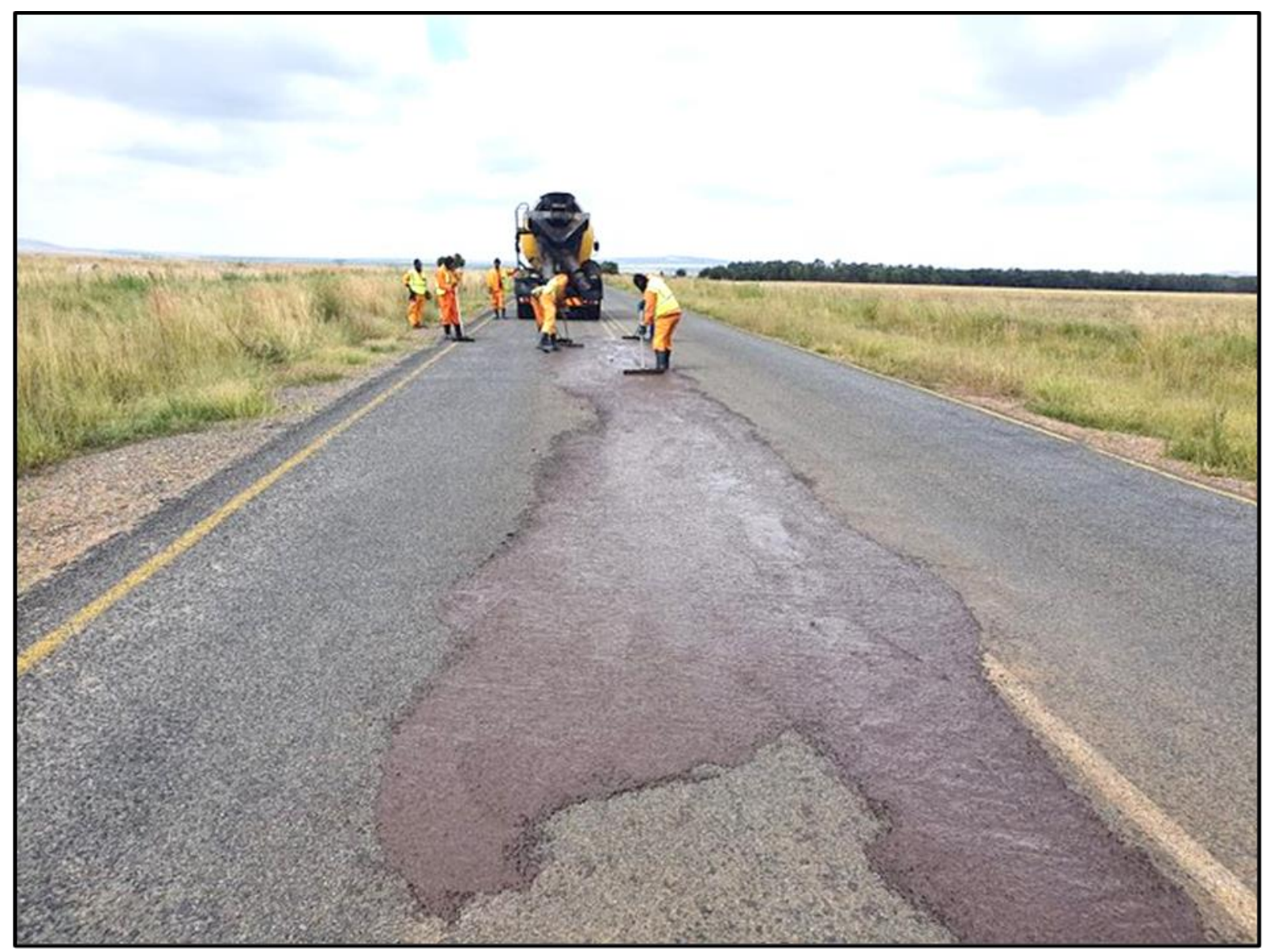

Figure 18: Filling of deformed areas on the road surface using a medium NME slurry mix as a pre-treatment to address severe deformation before applying a NME slurry across the whole width of the lane and road as shown in Figures 14 and 15.

\section{Recommendation for the Labour-Intensive Restoration of Compromised Existing Road Surfacings}

The preceding sections demonstrate the labour-intensive preventative and surface restoration practice that can be implemented immediately by road authorities using applicable and proven nanotechnology solutions with enhanced performance characteristics on existing surfaced road networks. The fact is that in the absence of well managed MMS's, road networks all over the world has deteriorated to a state where preventative maintenance is no longer a viable option on its own. Many roads have deteriorated to a stage where potholes are a common phenomenon, requiring a combination of the actions as discussed to restore the integrity of the pavement surfacing in a cost-effective alternative to partial reconstruction.

A combination of the labour-intensive options may be a viable to safeguard and restore numerous roads while presenting opportunities for rapid employment as a relief to social problems experienced all over the world. In order to restore the integrity of damaged roads, the process as illustrated in Figure 19 is recommended, following the instructions:

- Step 1: Restore the hydrophobicity of the road surface through the application of an anionic clear seal (diluted NPNS) by hand application to a point of saturation;

- Step 2: Clean and repair existing potholes using an anionic NME Pothole kit to provide a hydrophobic fill, and

- Step 3: Fill all cracked areas and restore some localised deformation by applying an anionic NME slurry mix before restoring the surfacing with an anionic NME slurry mix. 


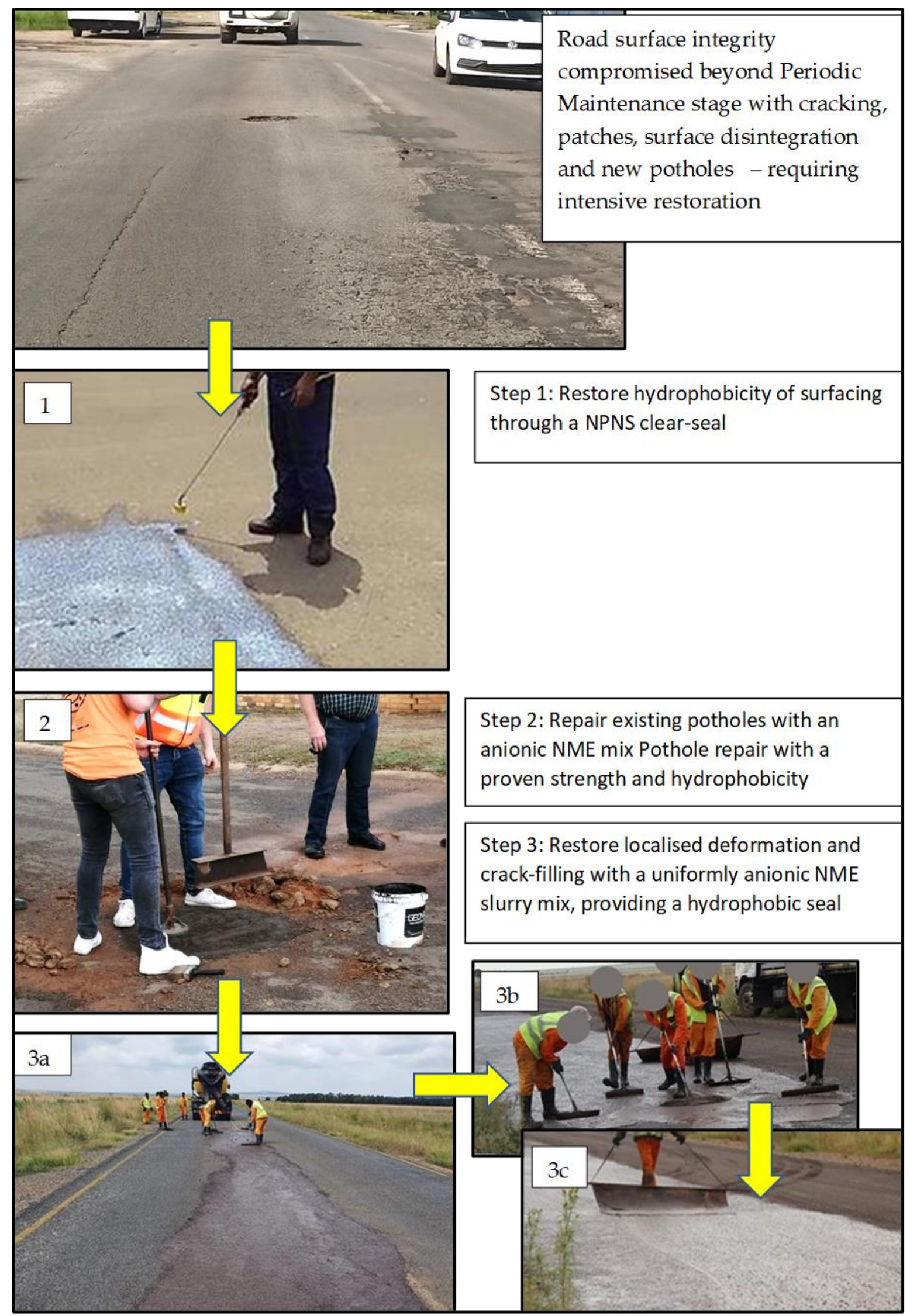

Figure 19: Recommended restoration of compromised road surfacings using available proven nanotechnology solutions suitable for labour-intensive application for rapid job creation providing valuable asset protection. 


\section{Conclusions}

Unemployment statistics are at record levels following the severe economic impact of lockdown all over the world as a result of the Pandemic. Governments, especially in developing regions of the world, are under increasing pressure by the electorate to provide employment opportunities and conditions favourable to economic growth. Infrastructure spending is seen as a major instrument available to Governments with the emphasis on high labour contents. Good transportation networks are crucial to economic growth and Road Authorities are under immense pressure to create more employment opportunities through road infrastructure development projects. However, specifications for primary roads in support of economic growth, require a high degree of mechanised equipment with little additional opportunities for labour-enhanced work.

However, many of the surfaced road networks in the developing world are lacking preventative maintenance, essential for the protection of the integrity of the surfacing of roads to preserve the structure below the surfacing. Consequently, numerous premature failures are too often the reality, rather than the exception, all over the world. The lack of preventative maintenance and the deterioration of existing surfaced roads, present Road Authorities with unique opportunities to create rapid employment and effective asset protection, utilising the enhanced water-repellent properties offered by available proven nanotechnology solutions. These solutions have been used in the built environment for the protection of buildings since the 1800's and are just as applicable to road infrastructure projects.

The same technologies developed for the protection of buildings houses can also be utilised to protect and repair roads. The unique characteristics of these nanotechnology solutions can provide enhanced resistance against the damaging effect of water, the main, well-documented cause of premature distress on roads. These nanotechnology solutions not only provide improved protection to road surfacings but are also ideally suited for labour-intensive applications. This article has measured and quantified the effect of the application of Nano-Polymer Nano-Silane (NSNP) clear-seals under challenging situations on unsurfaced compacted materials as well as severely cracked road surfaces. An immediate effect of a more than 10 times reduction in water-penetration was measured under these conditions. There is little doubt that the water-repellent effect of nano-silanes can be beneficiary to road maintenance activities. In combination with pothole kits, providing hydrophobic repairs to existing failures and nano-silane modified binders for slurry seals, Road Authorities could contribute not only to rapid employment opportunities, but at the same time address asset protection in support of sustainable economic development.

It follows that the applicable and proven nanotechnologies can effectively play a considerable role in the protection of the existing surfaced road infrastructure due to the inherent properties of the organofunctional silanes in terms of e.g.:

- Water-repellent (hydrophobic) characteristics that will render surfacings to repel water and prevent the ingress thereof;

- Nano-scale particle sizes that enable deep penetration into the existing surfacing and restore the water-resistant characteristics of existing surfacings;

- Adhesive and strength properties that can contribute considerably to the restoration of surfacings already requiring pothole repairs, and

- Applications suitable to be applied at ambient temperatures above freezing without application of pre-heating.

The application of maintenance activities incorporating suitable nanotechnology solutions can be highly effective towards labour-intensive operations. These actions could include the manufacturing and hand application of the following actions:

- Application of a deep-penetrating clear-seal (diluted NPNS) to restore the hydrophobic integrity of road surfacings. The rate of application depends on the condition of the surfacing and hence, is best observed and applied by hand-sprayer to prevent over- or under-application. Tests done on granular materials (as a worst-case 
scenario) have shown a 90 per cent (or more) reduction in water-ingress in a severely cracked surfacing;

- Repair of existing potholes using preprepared pothole kits using an anionic NME binder (with a shelf life of approximately 4 months), providing hydrophobic high strength protection which, in combination with a clear-seal and hydrophobic re-seal will give extended distress-free protection to the under-laying pavement layers, and

- Application on an NME modified binder medium slurry seal. These seals can be used to restore some existing uneven deformation caused by extensive cracking within wheel-tracks without removing the existing cracked areas, before applying a final NME slurry mix across the whole width of the road. The NME modified binder will provide a hydrophobic surfacing not achieved using traditional products.

The implementation of these maintenance activities can be done with little training, requiring no sophisticated equipment and incorporate the water-resistant characteristics of the organofunctional silanes. These actions can all be applied at ambient temperatures, requiring no extensive dangerous heating processes and creating numerous employment opportunities while protecting one of the most precious existing assets (transport infrastructure) of a country.

Author Contributions: G.J.J. under the directive of the Head of Department of Civil Engineering, W.J.vdM.S., has been leading the research into the provision of affordable road infrastructure at the faculty of Engineering, University of Pretoria. He has been instrumental in the design, implementation and construction supervision of roads using nanotechnologies. W.J.vdM.S. recognized the potential of nanotechnology solution in the field of pavement engineering more than a decade ago. G.J.J., through involvement in the private sector, has been responsible for the development of scientific principles, ensuring that implementation can be achieved at a minimum risk. All authors have read and agreed to the published version of the manuscript.

Funding: This research received no external funding.

Institutional Review Board Statement: Not applicable.

Informed Consent Statement: Not applicable.

Data Availability Statement: Not applicable.

Acknowledgments: The support of GeoNANO Technologies (Pty) Ltd., 18 Davies road, Wychwood, Germiston, 1401, South Africa, Tel: +27844078489, www.geonano.co.za, info@geonano.co.za, in support of students in the Department of Civil Engineering, University of Pretoria, Pretoria, South Africa, to test a wide variety of materials as part of final year projects and post-graduate theses, testing the various principles identified in this paper, is acknowledged.

Conflicts of Interest: The authors declare no conflict of interest. 


\section{References}

1. Steyn, W.J.vdM.; The upside of disruptive 4IR technology and innovation, University World News - Africa Edition, 2021.

2. Von Ebelman, J.J. Untersuchungen über die Verbinddungender Borsäure mit Aetther. Ann. Chem. Pharm. 1846, 57, 319-353.

3. Von Hoffman, W. Stone-preserving processes: Royal Institute of British Architects. Build. 1861, 19, $103-105$.

4. Wheeler, G. Alkoxysilanes and the Consolidation of Stone; The Getty Conservation Institute: Los Angeles, CA, USA, 2005.

5. Steyn, W.J. Potential applications of nanotechnology in pavement engineering. J. Transp. Eng. 2009, 135, 764-772.

6. National Centre for Asphalt Technology (NCAT). Effects of Nanotac Additive on Bond Strength and Moisture Resistance of Tach Coats; NCAT: Auburn, AL, USA, 2011.

7. Jordaan, G.J.; Kilian, A.; Machiavelli, N.; Dlamini, D. Practical Application of Nano-Technology in Roads in Southern Africa. In Proceedings of the 8th Transportation Technology Transfer (T2) Conference, Lusaka, Zambia, 4-8 March 2017.

8. Akhalwaya, I.; Rust, C.F. Laboratory evaluation of road construction materials enhanced with nano-modified emulsions (NME). In Proceedings of the Southern African Transportation Conference (SATC'18), Pretoria, South Africa, 9 - 12 July 2018.

9. Kidgell, M.M.; Steyn, W.J.vdM.; Jordaan, G.J. Effect of Nano-Modified Emulsions (NME) (nano-silanes) stabilisers on the properties of Dolomite, Proceedings of the 2019 Southern African Transportation Conference (SATC'19), Pretoria, South Africa, 2019.

10. Rust, F.C.; Akhalwaya, I.; Jordaan, G.J.; Du Plessis, L. Evaluation of a nano-silane-modified emulsion stabilised base and subbase under HVS traffic. In Proceedings of the 12th Conference on Asphalt Pavements for Southern Africa (CAPSA 2019), Sun City, South Africa, 13-16 October 2019.

11. Rust, F.C.; Smit, M.A.; Akhalwaya, I.; Jordaan, G.J.; Du Plessis, L. Evaluation of two nano-silane-modified emulsion stabilised pavements using accelerated pavement testing. Int. J. Pavement Eng. 2020, doi:10.1080/10298436.2020.1799210.

12. Jordaan, G.J.; Steyn, W.J.vdM; Broekman, A. Evaluation of cost-effective modified binder thin chip and cape seal surfacings on an anionic nano-modified emulsion (NME)-stabilised base-layer using accelerated pavement testing (APT). Appl. Sci. 2021, 11, 2514. doi:10.3390/app11062514.

13. Jordaan, G.J.; Steyn, W.J.vdM. Practical Application of Nanotechnology Solutions in Pavement Engineering: Construction Practices Successfully Implemented on Roads (Highways to Local Access Roads) Using Marginal Granular Materials Stabilised with New-Age (Nano) Modified Emulsions (NME). Preprints 2021, 2021100181 (doi: 10.20944/preprints202110.0181.v3).

14. Jordaan, G.J.; Steyn, W.J.vdM. Fundamental principles ensuring successful implementation of new-age (nano) modified emulsions (NME) for the stabilisation of naturally available materials in pavement engineering. Appl. Sci. 2021, $11,1745$. doi:10.3390/app11041745.

15. Jordaan, G.J.; Steyn, W.J.vdM. Engineering Properties of New-Age (Nano) Modified Emulsion (NME) Stabilised Naturally Available Granular Road Pavement Materials Explained Using Basic Chemistry. Appl. Sci. 2021, 11, 9699. https://doi.org/10.3390/app11209699.

16. Jordaan, G.J.; Steyn, W.J.vdM. Nanotechnology Incorporation into Road Pavement Design Based on Scientific Principles of Materials Chemistry and Engineering Physics Using New-Age (Nano) Modified Emulsion (NME) Stabilisation/Enhancement of Granular Materials. Appl. Sci. 2021, 11, 8525. https://doi.org/10.3390/app11188525.

17. Jordaan, G.J. Life-cycle cost analysis - An integral part of pavement rehabilitation design. In Proceedings of the 10th Conference on Asphalt Pavements for Southern Africa (CAPSA 2011), Drakensberg, South Africa, 11-14 September 2011.

18. Geonano Technologies (Pty) Ltd, GE-Clearsil®, Geonano Technologies, 18 Davies road, Wychwood, Germiston, 1401, South Africa, 2020.

19. Committee of Land Transport Officials (COLTO); Draft TRH14: Guidelines for Road Construction Materials; National Institute for Transport and Road Research (NITRR), CSIR: Pretoria, South Africa, 1985.

20. American Association of State and Highway Transportation Officials (AASHTO). M145-91: Standard Specification for Classification of Soils and Soil-Aggregate Mixtures for Highway Construction Purposes; AASHTO: Washington, DC, USA; 1995.

21. American Society for Testing Materials (ASTM). D3282-09: Standard Practice for Classification of Soils and Soil-Aggregate Mixtures for Highway Construction Purposes; ASTM: Pennsylvania, PA, USA, 2009.

22. The South African Institute of Civil Engineers, General Conditions of Contract for Construction Works, Published by the South African Institute of Civil Engineers, Third Edition, Midrand, South Africa, 2015.

23. Geonano Technologies (Pty) Ltd, GE-Skrik-vir-Niks ${ }^{\circledR}$ pothole repair kit, Geonano Technologies, 18 Davies road, Wychwood, Germiston, 1401, South Africa, 2021. 